\title{
Antimalarial NADPH-Consuming Redox-Cyclers As Superior Glucose-6-Phosphate Dehydrogenase Deficiency Copycats
}

\author{
Max Bielitza, Didier Belorgey, Katharina Ehrhardt, ${ }^{1,2, *}$ Laure Johann,, ${ }^{1, \dagger}$ Don Antoine Lanfranchi, \\ Valentina Gallo, ${ }^{3}$ Evelin Schwarzer, ${ }^{3}$ Franziska Mohring, ${ }^{4}$ Esther Jortzik, ${ }^{4}$ David L. Williams, ${ }^{5}$ \\ Katja Becker, ${ }^{4}$ Paolo Arese, ${ }^{3}$ Mourad Elhabiri, and Elisabeth Davioud-Charvet ${ }^{1}$
}

\begin{abstract}
Aims: Early phagocytosis of glucose-6-phosphate dehydrogenase (G6PD)-deficient erythrocytes parasitized by Plasmodium falciparum were shown to protect G6PD-deficient populations from severe malaria. Here, we investigated the mechanism of a novel antimalarial series, namely 3-[substituted-benzyl]-menadiones, to understand whether these NADPH-consuming redox-cyclers, which induce oxidative stress, mimic the natural protection of G6PD deficiency. Results: We demonstrated that the key benzoylmenadione metabolite of the lead compound acts as an efficient redox-cycler in NADPH-dependent methaemoglobin reduction, leading to the continuous formation of reactive oxygen species, ferrylhaemoglobin, and subsequent haemichrome precipitation. Structure-activity relationships evidenced that both drug metabolites and haemoglobin catabolites contribute to potentiate drug effects and inhibit parasite development. Disruption of redox homeostasis by the lead benzylmenadione was specifically induced in Plasmodium falciparum parasitized erythrocytes and not in non-infected cells, and was visualized via changes in the glutathione redox potential of living parasite cytosols. Furthermore, the redox-cycler shows additive and synergistic effects in combination with compounds affecting the NADPH flux in vivo. Innovation: The lead benzylmenadione 1c is the first example of a novel redox-active agent that mimics the behavior of a falciparum parasite developing inside a G6PD-deficient red blood cell (RBC) giving rise to malaria protection, and it exerts specific additive effects that are inhibitory to parasite development, without harm for non-infected G6PD-sufficient or -deficient RBCs. Conclusion: This strategy offers an innovative perspective for the development of future antimalarial drugs for G6PD-sufficient and -deficient populations. Antioxid. Redox Signal. 22, 1337-1351.
\end{abstract}

\section{Introduction}

$\mathbf{M}$ ALARIA REMAINS A MAJOR PARASITIC DISEASE that causes mortality, disability and economic losses in developing countries. Plasmodium falciparum is the most dangerous parasite species and is responsible for severe complications such as cerebral malaria with coma, severe anemia, and respiratory distress particularly frequent in young children. Because of rapidly spreading drug resistance in various Plasmodium parasite strains, the search for drugs with novel mechanism(s) of action is an urgent necessity.

\footnotetext{
${ }^{1}$ UMR 7509 Centre National de la Recherche Scientifique and University of Strasbourg, European School of Chemistry, Polymers and Materials (ECPM), Strasbourg, France.

${ }^{2}$ Department of Infectiology, University of Heidelberg, Heidelberg, Germany.

${ }^{3}$ Department of Oncology, University of Torino Medical School, Torino, Italy.

${ }^{4}$ Biochemistry and Molecular Biology, Interdisciplinary Research Center (IFZ), Justus Liebig University of Giessen, Giessen, Germany.

${ }^{5}$ Department of Immunology/Microbiology, Rush University Medical Center, Chicago, Illinois.

*Current affiliation: Institut de Biologie Moléculaire et Cellulaire, Strasbourg, France.

${ }^{\dagger}$ Current affiliation: DSM Nutritional Products, Site Aesch, Aesch, Switzerland.

(C) Max Bielitza et al. 2015; Published by Mary Ann Liebert, Inc. This Open Access article is distributed under the terms of the Creative Commons Attribution Noncommercial License (http://creativecommons.org/licenses/by-nc/4.0/) which permits any noncommercial use, distribution, and reproduction in any medium, provided the original author(s) and the source are credited.
} 


\section{Innovation}

The lead 3-[substituted-benzyl]-menadione 1c is the first example of a novel redox-active agent that mimics the behavior of a falciparum parasite developing inside a glucose-6-phosphate dehydrogenase (G6PD)-deficient red blood cell (RBC) giving rise to malaria protection, and exerts specific additive effects that are inhibitory to parasite development, without harming non-infected G6PDsufficient or -deficient RBCs.

The non-parasitized red blood cell (RBC) is exposed to oxidative damage due to a combination of high intracellular concentrations of both oxygen and redox-active haemoglobin $\mathrm{Hb}$ ) acting as a powerful generator of reactive oxygen species (ROS) (9). Antioxidant defense is ensured by high steadystate levels of reduced glutathione (GSH), which depend on adequate production and transfer of reducing equivalents from NADPH to oxidized glutathione (GSSG). Two enzymes of the pentose phosphate pathway (PPP), glucose-6phosphate dehydrogenase (G6PD) and 6-phosphogluconate dehydrogenase, generate NADPH, while glutathione reductase (GR) utilizes NADPH to regenerate GSH $(9,13)$. Disruption of the subtle equilibrium between oxidative damage and antioxidant defense occurs either by increasing the intracellular concentration of redox-active free haem, such as in Plasmodium parasitized RBCs (pRBCs), or by inhibiting G6PD and/or GR (20). Oxidative damage may lead to the suicidal transformation of RBC into a non-self cell flagged to be removed by the reticuloendothelial system in vivo $(5,32,40)$.

Deficiency of G6PD, the main producer of NADPH in $\mathrm{RBCs}$, is the most widespread genetic defect of the human $\mathrm{RBC}$, present in several hundred million people in areas where malaria was or still is endemic $(13,35,38)$. Carriers of the most frequent low-activity G6PD variants are haematologically normal but less protected against oxidative insult and particularly sensitive to oxidant drugs, chemicals, or food components that may induce severe anemia, predominantly due to phagocytic removal of large numbers of RBCs $(3,4)$. The remarkably similar geographic distribution of G6PD deficiency and malaria has suggested that the deficiency may protect against the disease, which has been substantiated by a number of case-control studies (25). The resistance of G6PDdeficient RBCs to severe malaria infection has been proposed to stem from the rapid phagocytic removal of early stages of pRBCs in vivo. Studies performed with oxidatively stressed or senescent RBCs have shown haemichromes to be key determinants of erythrophagocytosis, in the sense that a direct correlation is constantly present between haemichrome deposition and RBC phagocytosis expressed as number of ingested RBC per human monocyte $(14,22,38,39)$.

Ongoing studies of antiparasitic drugs that affect the redox homeostasis of pRBCs led to the identification of a series of 3-[substituted-benzyl]-menadiones (benzylMD) as promising novel antimalarial agents $(17,36)$. The potent antiparasitic activities of the lead compounds were established with malaria parasites in culture and confirmed with the $P$. berghei-infected murine malaria model. We proposed that this antimalarial selectivity of benzylMD comes largely from its specific bioactivation within Plasmodium pRBCs.

The mechanism of antimalarial action of the benzylMD series was proposed to involve a cascade of redox reactions
(Fig. 1, steps (1)-(3) starting with the benzylic oxidation of the lead benzylMD 1c in pRBCs. The generated benzoylmenadione 2c and analogues (abbreviated as 3-[substitutedbenzoyl]-menadione [benzoylMD], step (1) were found to act as the most effective substrates of $P$. falciparum $\mathrm{GR}$ described so far (Fig. 1, step (2) (36). Subsequently, methaemoglobin $\left(\mathrm{Fe}^{\mathrm{III}}\right)$ (metHb) reduction into oxyhaemoglobin $\left(\mathrm{Fe}^{\mathrm{II}}\right)(\mathrm{Hb})$ was evidenced to be catalyzed by the reduced benzoylMD $3 \mathbf{c}$ in a continuous NADPH-consuming redox cycle (Fig. 1, step (3)). Reversion of $\mathrm{Hb}$ oxidation may prevent $\mathrm{Hb}$ digestion and, ultimately, lead to arrest of parasite growth, as observed in morphologically altered dying early (ring) stages of $P$. falciparum shown in Figure 2a (17). Furthermore, the generation of a third metabolite, namely the benzo[ $c]$ xanthen-7-one (benzoxanthone) derivative $\mathbf{4 c}$, has been envisioned as one possible metabolite generated through an oxidative phenolic coupling reaction from the reduced benzoylMD $3 \mathbf{c}$ radical (Fig. 1, step (4)). The properties of benzoxanthone $\mathbf{4 c}$ have been investigated here in detail.

In this present multidisciplinary approach, we investigated how, in relation to their electro-, bio-, and physicochemical behavior, the lead benzylMD and its metabolites (i) disturb the redox homeostasis of the parasite by cycling $\mathrm{Hb}$-iron between three different oxidation states (+II, + III, and + IV, influencing both spin state and axial ligation), (ii) enhance important NADPH-consuming processes that specifically disrupt the antioxidant defense of pRBCs, (iii) and lead to denaturation of $\mathrm{Hb}$ and formation of haemichromes on ring-pRBCs membranes, which are known to enhance phagocytosis. To the best of our knowledge, this is the first report of lead antimalarial agents that mimic the mechanism of natural malaria protection provided by G6PD deficiency and exert specific additive effects that are inhibitory to parasite development.

\section{Results}

\section{Bioactivation of benzyIMD 1c to benzoyIMD 2c, a key metabolite for the antimalarial activity of benzyIMDs}

Thorough physicochemical investigations of the lead benzylMD 1c, its putative metabolites 2c-4c (Fig. 2), and model compounds stable in open air, 3c* (fluoro analogue of 3c) and methoxymethyl monoether of 3c (3c-MOM) shown in Table 1, were carried out to evaluate their capacities to (i) act as redox-cyclers, (ii) interact with ferric targets such as $\mathrm{Fe}^{\mathrm{III}}, \mathrm{Fe}^{\mathrm{III}}$-haem, or metHb (Figs. 2 and 3), and (iii) correlate with antimalarial activities (Fig. 2a).

Synthesis of model metabolites and benzoxanthones 4c-7. Four related benzoxanthones and intermediates were synthesized using the chemical route and protocols described in the Supplementary Data (Supplementary Fig. S1; Supplementary Data are available online at www.liebertpub .com/ars).

Benzylic oxidation renders the drugs more oxidant and increases affinity for GR. Electrochemical properties of benzylMD 1c and its putative metabolites $\mathbf{2 c - 4 c}$ were first investigated (Supplementary Fig. S2) to correlate their oxidant character with the substrate activities reported in human and parasite GR ( $h \mathrm{GR}$, PfGR) assays (36). BenzylMD 1c is a poor substrate with respect to $h \mathrm{GR}$ (i.e. the parent menadione is characterized by a low $k_{\text {cat }}$ value of $0.16 \mathrm{~s}^{-1}$ ) (10). 


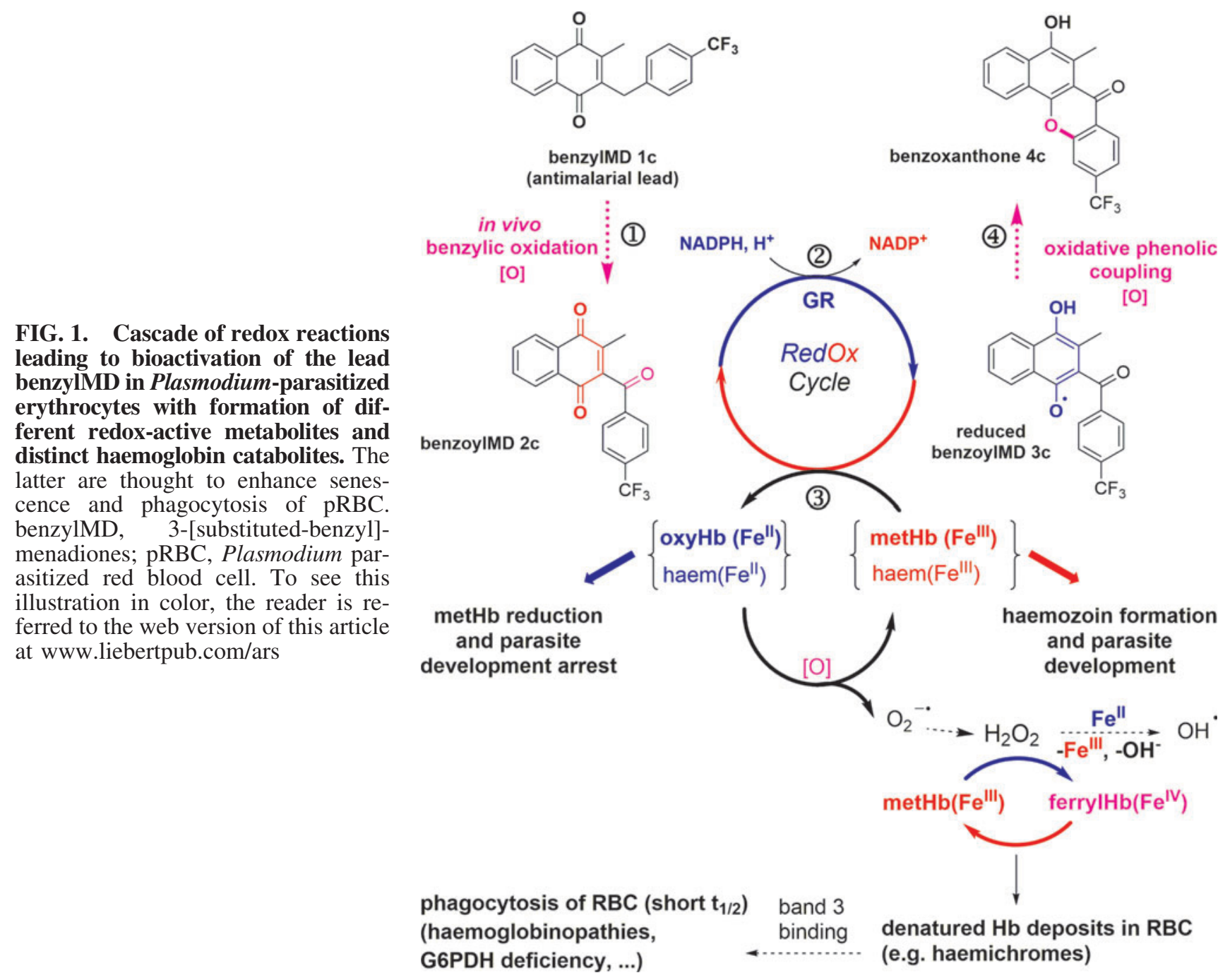

Additionally, menadione $\left(E_{1 / 2}^{1}=-0.60 \mathrm{~V}\right.$ and $\left.E^{2}{ }_{1 / 2}=-1.33 \mathrm{~V}\right)$ and benzylMD 1c $\left(E^{1}{ }_{1 / 2}=-0.61 \mathrm{~V}\right.$ and $\left.E_{1 / 2}^{2}=-1.35 \mathrm{~V}\right)$ display similar redox properties, thus confirming comparable redox behavior toward $h$ GR and PfGR (Fig. 2b). By contrast, biooxidation of the benzyl chain markedly alters the redox properties of the menadione core in benzylMD 1c versus benzoylMD 2c (i.e., anodic shifts of $\sim 200 \mathrm{mV}$ are observed for both $1 \mathrm{e}^{-}$and $2 \mathrm{e}^{-}$redox processes, $E_{1 / 2}^{1}=-0.43 \mathrm{~V}$ and $E^{2}{ }_{1 / 2}=-1.12 \mathrm{~V}$ for $2 \mathrm{c}$, Fig. 2b) and leads to significantly enhanced efficiency as substrates for GR, for 2c and its benzoylMD analogues [cited as 3a, 3b, 3d, 3g, 4a, 6a in Table 1 from ref. (36)]. These large potential shifts measured for $\mathbf{2 c}$ likely correspond to electronic modulation induced by the $\mathrm{CF}_{3}$ substituent borne by the benzoyl moiety that facilitates the reduction of the quinone (1).

The benzoyIMD $\mathbf{2 c}$ in its reduced state $\mathbf{3 c}$ is a potent Fe $\mathrm{F}^{\text {III }}$ chelator. Numerous sources of $\mathrm{Fe}^{\mathrm{III}}$ are available within the pRBCs (metHb, Hb, haem, haemozoin, labile iron pool...) and are relevant reporters of infection events, drug activity, and trafficking. We therefore considered the possibility for benzylMD 1c-derived metabolites to act as metal chelators. $\mathrm{Fe}^{\mathrm{III}}$ chelation might catalyze bioactivation key steps or assist the transport of the drug within the main pathogen's compartments (siderophore-like transport). Among the metabo- lite series, only the benzoylMD in its oxidized (2c) or reduced (3c) form displays an oxygen-rich bidentate site that is suitable for $\mathrm{Fe}^{\mathrm{III}}$ chelation. The metabolite $2 \mathrm{c}$ was shown to be an ineffective Fe ${ }^{\mathrm{III}}$ chelator, while 3c-MOM (i.e., a stable form of the $2 \mathrm{e}^{-}$reduced form of $\mathbf{3 c}$ in open air solution) chelated ferric cation in putative $\mu$-oxo 2:2 (3c-MOM:Fe ${ }^{\mathrm{III}}$ ) fashion (Fig. 2c) with a global stability constant of $\log \beta_{22}=8.4 \pm 0.2$. This is further supported by the formation of a phenolate-to$\mathrm{Fe}^{\mathrm{III}}$ charge transfer absorption in the visible region (Fig. 2c).

BenzylMD-derived metabolites efficiently prevent crystallization of haematin to $\beta$-haematin. Even though benzylMD 1c and its putative metabolites firmly interact with haematin ( $\pi$-stacking interactions), only oxidized and reduced benzoylMD (2c and 3c*), and benzoxanthone $\mathbf{4 c}$ are effective inhibitors of haematin crystallization under quasi-physiological conditions (Table 1). With respect to benzoxanthone $\mathbf{4 c}$, the antimalarial potency of hydroxyxanthones was reported to be linked to their capability to inhibit haematin crystallization in vitro, thus suggesting that these compounds exert their antimalarial activity by preventing haemozoin formation (47).

Among the benzylMD-derived metabolites, benzoxanthone 4c displayed the highest capacity to inhibit $\beta$-haematin formation (i.e., 70\% inhibition at a drug:haematin ratio of 3), but was less efficient than the gold standards amodiaquine (AQ) 


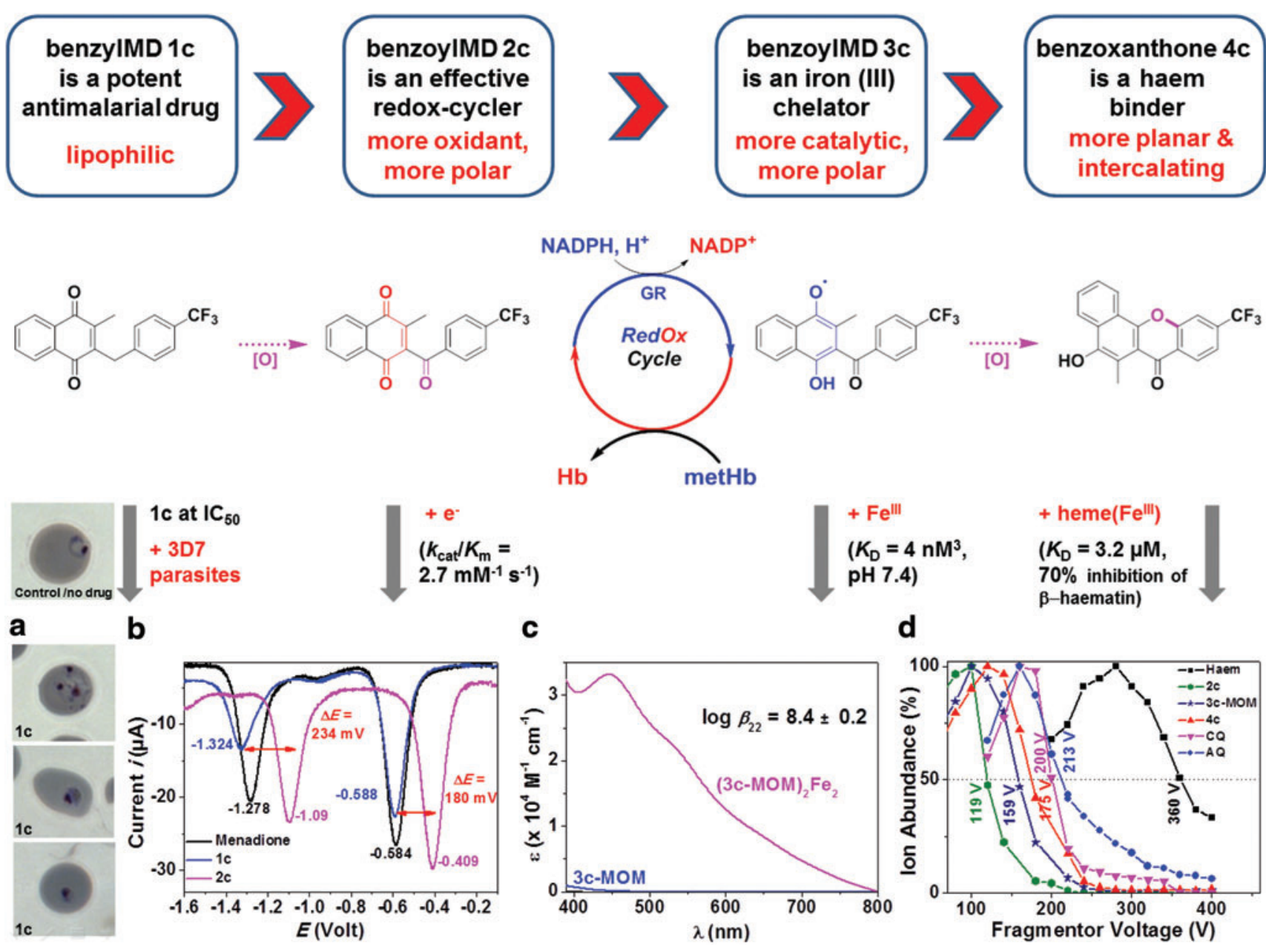

FIG. 2. Drug bioactivation of benzylMD 1c through a cascade of redox reactions leading to the formation of benzoylMD 2c, reduced benzoylMD 3c, and benzoxanthone 4c. (a) Microscopic images of Plasmodium falciparum 3D7 strain ring-pRBCs, not treated by the drug (control) and benzylMD 1c-treated at $50 \mathrm{n} M$ for $24 \mathrm{~h}$, showing altered morphologies and pyknotic parasites. (b) Square wave voltammograms of menadione $(1.44 \mathrm{~m} M), 1 \mathrm{c}(1.12 \mathrm{~m} M)$, and 2c $(1.30 \mathrm{~m} M)$. Solvent: Ar-purged DMSO; $T=25.0^{\circ} \mathrm{C} ; I=0.1 M \mathrm{NBu}_{4} \mathrm{PF}_{6} ; v=200 \mathrm{mV} \mathrm{s}{ }^{-1}$; Reference $=\mathrm{Ag} / \mathrm{AgCl} .(\mathbf{c}) \mathrm{Ab}-$ sorption electronic spectra of 3c-MOM and its putative complex with $\mathrm{Fe}^{\mathrm{III}}$. No complexation has been found with the related oxidized form 2c. (d) Stability responses and calculated $\mathrm{DV}_{50}$ of the [haematin.drug $]^{+}$adducts $\left(\operatorname{drug}=\mathbf{2 c}\left([\mathrm{haematin}+\mathbf{2 c}]^{+}\right.\right.$ 960.5/119 V), 3c-MOM ([haematin + 3c-MOM $]^{+}$1006.55/159 V), 4c ([haematin + 4c] ${ }^{+}$960.5/175 V) obtained from an ESI$\mathrm{CID}$ approach with $\mathrm{CQ}=$ chloroquine ([haematin $\left.+\mathrm{CQ}]^{+} 935.4 / 200 \mathrm{~V}\right)$ and $\mathrm{AQ}=$ amodiaquine $\left([\text { haematin }+\mathrm{AQ}]^{+} 971.3 /\right.$ $213 \mathrm{~V}$ ) used as gold standards; $10 \mu M$ haematin $+10 \mu M$ drug in $\mathrm{H}_{2} \mathrm{O} / \mathrm{CH}_{3} \mathrm{CN}(50 / 50)+0.1 \%$ formic acid, fragmentor voltage ranges from 20 to $400 \mathrm{~V}$ with $20 \mathrm{~V}$ increments. No complex has been identified for benzylMD 1c by ESI-MS; see also Table 1. 3c-MOM, methoxymethyl monoether of 3c; AQ, amodiaquine; benzoxanthone, benzo[c]xanthen-7-one; benzoylMD, 3[substituted-benzoyl]-menadione; CID, collision-induced dissociation; CQ, chloroquine; DMSO, dimethyl sulfoxide; DV ${ }_{50}$, dissociation voltage at 50\%; ESI-MS, electrospray ionization-mass spectrometry. To see this illustration in color, the reader is referred to the web version of this article at www.liebertpub.com/ars

and chloroquine (CQ) (28). This lower activity could be due to the degradation of the phenol $\mathbf{4} \mathbf{c}$ in aerated aqueous solutions, as observed in control liquid chromatography-tandem mass spectrometry (LC-MS/MS) assays over $24 \mathrm{~h}$ (Supplementary Fig. S3). A complementary electrospray ionization-mass spectrometry (ESI-MS)-collision-induced dissociation (CID) approach assessed the 1:1 haematin:drug stoichiometry, which was previously established by absorption titrations (Table 1; Supplementary Fig. S4) $(28,37)$. Furthermore, the dissociation voltage at $50 \%$ sequence $(\mathrm{AQ}>\mathrm{CQ}>>\mathbf{4 c}>\mathbf{3 c}$ MOM $>2 \mathbf{c}$ ) shown in Figure $2 d$ perfectly matches with the one determined from a $\beta$-haematin inhibition assay, thus strengthening our observations (Table 1; Supplementary Fig. S5).
It is noteworthy that neither the $\beta$-haematin inhibition assay nor the CID-MS method demonstrated any ability of the benzylMD 1c to interact with haematin directly. These results indicate that the stepwise oxidation processes convert the lead benzylMD 1c to more efficient metabolites (more conjugated $\rightarrow$ more oxidant $\rightarrow$ more planar) through a prodrug effect.

Action of toxic potential drug and model metabolites against parasite survival. BenzylMD 1c, its potential metabolites, and synthetic intermediates until the benzoxanthone derivatives were tested for parasite growth inhibition in RBCs parasitized with the CQ-sensitive 3D7 or the multidrugresistant Dd2 $P$. falciparum strains (Table 1). Different 
Table 1. Antimalarial Activities Against 3D7 and Dd2 Plasmodium falciparum Strains, Haematin Binding, and Crystallization Inhibition Properties of 3-[Substituted-Benzyl]-Menadiones 1C and Synthetic Intermediates of Benzoxanthone 4C
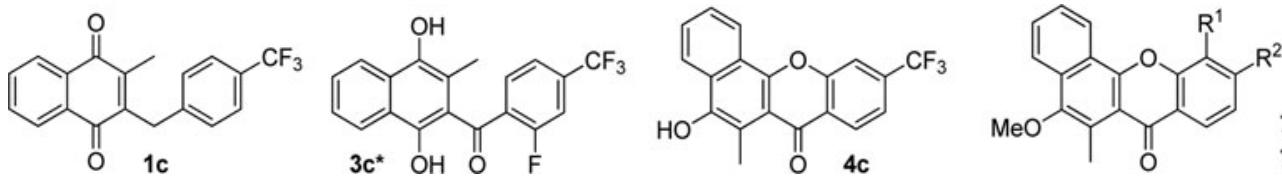

7c $\mathrm{R}^{1}=\mathrm{H}, \mathrm{R}^{2}=\mathrm{CF}_{3}$ 7i $\mathrm{R}^{1}=\mathrm{CF}_{3}, \mathrm{R}^{2}=\mathrm{H}$

\begin{tabular}{|c|c|c|c|c|c|}
\hline \multirow[b]{2}{*}{ Compound } & \multirow[b]{2}{*}{$\begin{array}{l}I C_{50} 3 D 7 \\
(n \mathrm{M})^{\mathrm{a}}\end{array}$} & \multirow[b]{2}{*}{$\begin{array}{l}I C_{50} D d 2 \\
(n \mathrm{M})^{\mathrm{a}}\end{array}$} & \multicolumn{2}{|c|}{ Haematin binding ${ }^{\mathrm{b}, \mathrm{c}}$} & \multirow{2}{*}{$\begin{array}{c}\beta \text {-Haematin } \\
\text { inhibition }^{\mathrm{d}} \\
I_{50} \\
(\% \text { max inhib.) }\end{array}$} \\
\hline & & & $\begin{array}{c}\log \beta_{\text {haematin.drug }} \\
\text { [haematin:drug]/K } K_{D}(\mu \mathrm{M})^{\mathrm{b}}\end{array}$ & $\begin{array}{l}m / z \text { adduct/ } \\
D V_{50}(V)^{\mathrm{c}}\end{array}$ & \\
\hline 1c & & 65 & $6.80 \pm 0.20 /[1: 1] / 0.1$ & No c & No in \\
\hline $3 \mathrm{c}^{*}$ & 1,159 & 1,2 & ]/0.80 & nd & $2.70(57 \%)$ \\
\hline & $431 \pm 120$ & $613 \pm 79.0$ & $5.50 \pm 0.20 /[1: 1] / 3.20$ & {$[\text { haematin }+\mathbf{4 c}]^{+} 960 / 175$} & $2.30(70 \%)$ \\
\hline $7 \mathbf{c}$ or $7 \mathbf{i}$ & & & $5.70 \pm 0.30 /[1: 1] / 2.00$ for $7 \mathbf{c}^{\mathrm{b}}$ & & $\begin{array}{l}32 \% \text { inhib. at } \\
5 \text { equiv. for } 7 \mathbf{c}^{\mathrm{b}}\end{array}$ \\
\hline CQ & $7.90 \pm 1.50$ & $134 \pm 11.3$ & $12.7 \pm 0.20 /[2: 1] / 1.30$ & {$\left[\right.$ haematin + CQ] $^{+} 935 / 200$} & $1.60(86 \%)^{\mathrm{d}}$ \\
\hline
\end{tabular}

${ }^{\mathrm{a}}$ Values are means of at least two independent determinations in triplicate. The $\mathrm{IC}_{50}$ value of the antimalarial drug $\mathrm{CQ}$ is indicated as a reference.

${ }^{\mathrm{b}} 0.2 \mathrm{M}$ sodium hepes buffer $\mathrm{pH} 7.5$, see ref. (28).

${ }^{\mathrm{c}} \mathrm{ESI}_{-\mathrm{MS}}{ }^{+} \mathrm{CID} ; \mathrm{CH}_{3} \mathrm{CN} / \mathrm{H}_{2} \mathrm{O}(1 / 1 \mathrm{v} / \mathrm{v})+0.1 \%$ formic acid; [haematin] $=[\mathrm{drug}]=10 \mu M$, see ref. (37). The DV 50 were calculated from the stability responses shown in Figure $2 \mathrm{~d}$.

${ }^{\mathrm{d}} 12.9 \mathrm{M}$ sodium acetate buffer $\mathrm{pH} 4.5,60^{\circ} \mathrm{C}, 1 \mathrm{~h}$ then $0.2+0.02 \mathrm{M}$ sodium hepes buffer $\mathrm{pH} 7.5$ containing $5 \%$ pyridine (v/v) as reporting reagent; see ref. $(19,28)$.

${ }^{\mathrm{e}}$ Compounds at $5 \mu M$ precipitated in the culture media.

CID, collision-induced dissociation; $\mathrm{CQ}$, chloroquine; $\mathrm{DV}_{50}$, dissociation voltage at 50\%; ESI-MS, electrospray ionization-mass spectrometry; nd, not determined.

experimental conditions explain the slightly higher $\mathrm{IC}_{50}$ values of $69.2 \mathrm{n} M$ for the lead benzylMD 1c compared to the previously reported value of $29 \mathrm{nM}$ (36).

The most potent antimalarial benzoxanthone against the multidrug-resistant $\mathrm{Dd} 2$ strain is phenol $4 \mathbf{c}\left(\mathrm{IC}_{50}\right.$ value $=$ $613 \mathrm{nM}$ ), although it is significantly less active compared to benzylMD 1c. As mentioned earlier, the observed slow phenol oxidation of benzoxanthone $\mathbf{4 c}$ in aqueous buffers (33\% disappearance at $\mathrm{pH} 5.2$ or 7.4 after $24 \mathrm{~h}$, Supplementary Fig. S3) might lead to the apparent lower activity in parasite growth assays. This result is very promising, as $\mathbf{4 c}$ is proposed to be one of the key metabolites generated from the lead prodrug 1c. As expected, none of the methoxylated benzoxanthones 7 showed significant antimalarial activities, likely because the protected phenol was not cleaved in the cell. An additional explanation is that benzoxanthones might not be taken up by pRBCs. Benzoxanthones $4 \mathbf{c}, 7$ and several key intermediates were non-toxic against human lung fibroblast $h$ MRC5 cells $\left(\mathrm{IC}_{50}\right.$ values $\left.>64 \mu M\right)$.

\section{Generation of haemoglobin catabolites}

The benzoyIMD $\mathbf{2 c}$ is a more effective substrate in the GRcoupled metHb reduction assay than the parent benzyIMD 1c. In addition to its capacity to alter the physicochemicaldriven haematin biocrystallization process, the reduced benzoylMD 3c was shown to target other relevant ferric species such as metHb and to partake in electron transfer reactions. Shifting the $\mathrm{Hb} \leftrightarrows$ metHb equilibrium toward $\mathrm{Hb}$ formation slows metHb digestion within the acidic digestive vesicles and inhibits parasite growth. We therefore carried out the metHb reduction assay, which represents a valuable reporter for the capacity of our compounds to reduce metHb under quasi-physiological conditions, even in the presence of an excess of GSSG ( $20 \mu M$, Fig. 3a), which competes for GR-catalyzed reduction, confirming the essential requirement of the redox-cycler in NADPH-dependent GRmediated metHb reduction (See Supplementary Figs S6 and S7 with all controls in the absence of NADPH, benzoylMD 2c, or in the presence of GSH/GSSG) $(11,28,36)$. A clear trend can be drawn between high efficiency $\left(k_{\mathrm{cat}} / K_{\mathrm{m}}\right)$ and affinity $\left(K_{\mathrm{m}}\right)$ for GR, fine-tuned electrochemical properties, and capacity to efficiently reduce metHb. While benzylMD 1c was ineffective, its benzoylMD analogue 2c efficiently reduced the ferric haemoglobin in the presence of the GR/ NADPH system $\left(k_{\mathrm{metHb}}=1.2 \pm 0.3 \times 10^{-3} \mathrm{~s}^{-1}\right)$ (Table in Fig. 3a). The ability of the fluorine-based benzoylMD $3 \mathbf{c}^{*}$, an air-stable analogue for the $2 \mathrm{e}^{-}$reduced metabolite $\mathbf{3 c}$, to efficiently and rapidly reduce metHb $\left(k_{\mathrm{metHb}}=13 \pm 2 \times 10^{-3}\right.$ $\mathrm{s}^{-1}$ ) without the assistance of GR further substantiated the suggested mechanism of action (Supplementary Fig. S6) (36). In addition to its capacity to inhibit haematin crystallization, benzoxanthone $\mathbf{4 c}$ shifted the $\mathrm{Hb} \leftrightarrows$ metHb equilibrium toward $\mathrm{Hb}$ formation $\left(k_{\mathrm{metHb}}=2.2 \pm 0.2 \times 10^{-3} \mathrm{~s}^{-1}\right.$, Supplementary Fig. S6).

Both NADPH and ROS contribute to haemichrome formation in the metHb reduction assay coupled with NADPH/ GR. During the GR-catalyzed metHb reduction assay (15 hlong redox-cycling), further significant observations were made (Fig. 3b; Supplementary Fig. S8). First, the absorbance maximum of $\mathrm{Hb}$ was bathochromically shifted ( $\sim 416$ versus 


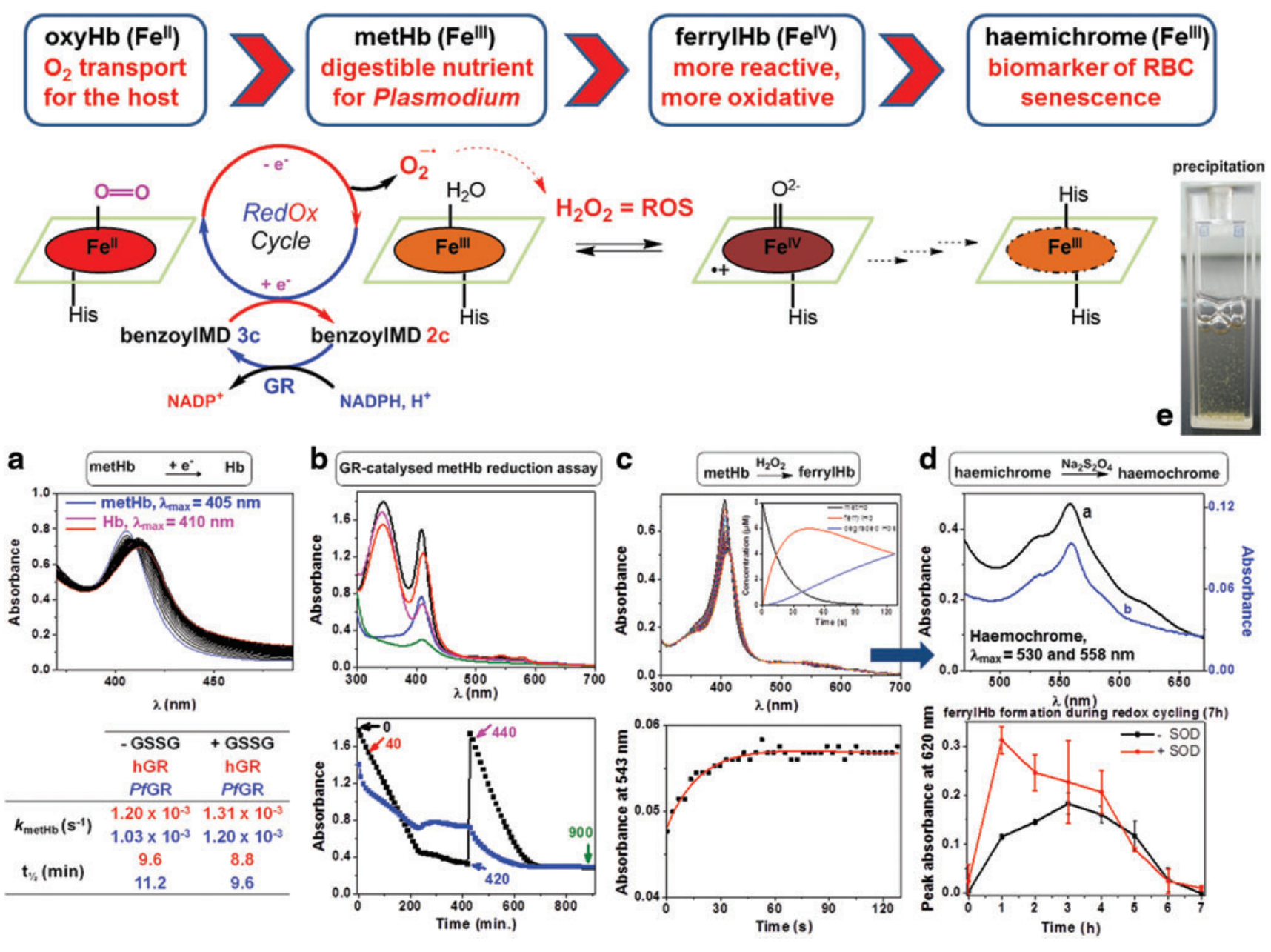

FIG. 3. BenzoylMD 2c-mediated haemoglobin reduction and catabolism under oxidative stress conditions. (a) (Upper figure) metHb reduction assay in the presence of $2 \mathrm{c}(40 \mu M)$, GR buffer (pH 6.9), metHb (8 $\mu M)$, NADPH (120 $\mu M)$, PfGR $(100 \mathrm{nM})$, GSSG $(20 \mu M)$ : 0 min (blue), $60 \mathrm{~min}$ (magenta), $120 \mathrm{~min}$ (red); (lower table) statistical analysis of the absorption spectra data set versus time allowed the calculation of the apparent first-order rate constant $k_{\mathrm{metHb}}$ and $\mathrm{t}_{1 / 2}$ for metHb reduction. (b) (Upper figure) spectra of metHb (black), $\mathrm{Hb}(\mathrm{red})$, the reaction mixture at the end of the first cycle of NADPH consumption (blue), the reaction mixture at the beginning of the second cycle of NADPH consumption (magenta), the reaction mixture at the end of the second cycle of NADPH consumption (green) recorded in a $15 \mathrm{~h}$-long metHb reduction assay monitored by UV-Vis absorption; GR buffer ( $\mathrm{pH}$ 6.9), metHb $(32 \mu M)$, 2c $(40 \mu M)$, NADPH (final concentrations: first addition: $480 \mu M$; second addition: $466 \mu M)$, PfGR $(400 \mathrm{n} M)$, SOD $(7.2 \mathrm{U} / \mathrm{ml}), 25.0^{\circ} \mathrm{C}$, black: first cycle, red: second cycle; (lower figure) continuous reduction of metHb (blue line measured at $420 \mathrm{~nm}$ ) catalyzed by PfGR on flux of NADPH (black line, measured at $340 \mathrm{~nm}$ ); time 0 and 440 min correspond to the addition of NADPH (final concentration $466 \mu M$ ), which is totally consumed in $c a$. 420 min. (c) (Upper figure) stopped-flow measurement of ferrylHb formation; (upper figure inset) time-dependent diagrams of different $\mathrm{Hb}$ species: disappearance of metHb (black curve), formation of ferrylHb (red curve), and formation of $\mathrm{Hb}$ degradation products (blue curve); (lower figure) ferrylHb formation kinetic trace (metHb oxidation by $\mathrm{H}_{2} \mathrm{O}_{2}$ ) at $543 \mathrm{~nm}$; phosphate buffer ( $\mathrm{pH} 7$ ), metHb $(8 \mu M), \mathrm{H}_{2} \mathrm{O}_{2}(80 \mu M), 25.0^{\circ} \mathrm{C}$. (d) (Upper figure) indirect proof of haemichrome formation by conversion to haemochrome: black curve: $15 \mathrm{~h}$ oxidation reaction; metHb $(80 \mu M)$ by $\mathrm{H}_{2} \mathrm{O}_{2}(800 \mu M)$, phosphate buffer $(\mathrm{pH} 7), 25.0^{\circ} \mathrm{C}$, then addition of $\mathrm{Na}_{2} \mathrm{~S}_{2} \mathrm{O}_{4}$ (few crystals) $\rightarrow$ characteristic haemochrome spectrum, blue curve: reference haemochrome spectrum: metHb (8 $\mu M)$, phosphate buffer (pH 7), $25.0^{\circ} \mathrm{C}$, SDS (16:1), then addition of $\mathrm{Na}_{2} \mathrm{~S}_{2} \mathrm{O}_{4}$; (lower figure) determination of the relative amount of ferrylHb during redox-cycling catalyzed by $\mathbf{2 c}$ in the continuous metHb reductions assay shown in Figure $3 b$, by derivatization to sulfhaemoglobin with $\mathrm{Na}_{2} \mathrm{~S}$ (aq., $1.94 \mathrm{mM}$ ) (details in Supplementary Fig. S8). (e) Image of the cuvette showing the greenish precipitate during the $15 \mathrm{~h}$-long redox-cycling. ferrylHb, ferrylhaemoglobin( $\left.\mathrm{Fe}^{\mathrm{IV}}\right)$; GR, glutathione reductase; GSSG, oxidized glutathione; $\mathrm{H}_{2} \mathrm{O}_{2}$, hydrogen peroxide; $\mathrm{Hb}$, oxyhaemoglobin( $\left.\mathrm{Fe}^{\mathrm{II}}\right)$; metHb, methaemoglobin $\left(\mathrm{Fe}^{\mathrm{III}}\right.$ ); $\mathrm{Na}_{2} \mathrm{~S}$, sodium sulfide; $\mathrm{Na}_{2} \mathrm{~S}_{2} \mathrm{O}_{4}$, sodium dithionite; PfGR, Plasmodium falciparum glutathione reductase; SDS, sodium dodecyl sulfate; SOD, superoxide dismutase. To see this illustration in color, the reader is referred to the web version of this article at www.liebertpub.com/ars

$410 \mathrm{~nm}$ ), indicating a mixture of different $\mathrm{Hb}$ species. Second, metHb was regenerated at the end of the cycle but with lower absorbance intensity. A further addition of 15 equiv. of NADPH to the reaction solution again switched on the redoxcycling (red cycle), which continued until all NADPH was consumed. Figure 3b displays two kinetic traces at 340 (decrease of NADPH, blue line) and $420 \mathrm{~nm}$ (decay of Hb species, black line). During the first cycle, the absorbance maximum of the $\mathrm{Hb}$ species decreased from 1.49 to 0.80 and then to 0.30 after the second cycle (control experiments 
showed that metHb is stable at $\mathrm{pH} 6.9$ and that the absorbance decrease is negligible, see Supplementary Fig. S9). These data clearly indicated that NADPH was the limiting factor and that the haem structure was altered.

The benzoyIMD $\mathbf{2 c}$ is the catalyst allowing the formation of ferrylhaemoglobin in the reduction assays. When metHb was reduced by benzoylMD 3c to Hb, the latter auto-oxidized to metHb. This process was accompanied by the formation of superoxide radical anions $\mathrm{O}_{2}^{\bullet-}$, which occurs during $\mathrm{Hb}$ digestion in the acidic digestive vesicles of the parasite. These radicals are known to dismutate to hydrogen peroxide $\left(\mathrm{H}_{2} \mathrm{O}_{2}\right)$ depending on the reaction conditions (catalyzed by superoxide dismutase [SOD], or spontaneous at acidic $\mathrm{pH}$ ) (45). Likely, both ROS reacted with the different $\mathrm{Hb}$ species, resulting in destruction of the haem structure via Fenton reaction and in the formation of ferrylhaemoglobin $\left(\mathrm{Fe}^{\mathrm{IV}}\right)$ (ferrylHb) (Fig. 3d) (45). Fast kinetic experiments by reacting metHb with $\mathrm{H}_{2} \mathrm{O}_{2}$ under pseudo-first-order conditions provided insights into the rapid formation and decay of ferrylHb (Fig. 3c). FerrylHb is a short-lived and reactive intermediate that could be trapped during the reaction by derivatization with sodium sulfide $\left(\mathrm{Na}_{2} \mathrm{~S}\right)$ to its sulfo-derivative $\left(\lambda_{\max }=\right.$ $620 \mathrm{~nm}$ ), in the presence or absence of SOD, as illustrated in Figure $3 \mathrm{~d}$ (23). FerrylHb was rapidly formed and vanished, mainly by auto-reduction to metHb, as soon as the redoxcycling was no longer fed by NADPH. It is known that ferryl $\mathrm{Hb}$ can undergo various reactions, for example, autoreduction and cross-linking, and damages the human cellular cytoskeleton (16).

FerrylHb has therefore to be considered a key species formed during the intricate redox processes. Importantly, the continuous $15 \mathrm{~h}$-long redox-cycling can be maintained as long as NADPH is available in the coupled assay. After consumption of 15 equiv. excess of NADPH (with respect to metHb) within $4 \mathrm{~h}$, the reaction mixture of $\mathrm{Hb}$ catabolites is complex; among several reactions taking place in parallel, ferryl $\mathrm{Hb}$ is auto-reduced to metHb and degraded $\mathrm{Hbs}$ while $\mathrm{Hb}$ is auto-oxidized into metHb, in about 5-6h (Fig. 3b black cycle and blue cycle) (30). Finally, precipitation of a greenish solid slowly took place at the end of the process, which was more severe when more NADPH was added (Fig. 3e, see the cuvette).

Thus, the ability of the lead antimalarial benzylMD-derived metabolites to catalyze the formation of ROS during the autooxidation of $\mathrm{Hb}$ to metHb correlates with increased formation of ferrylHb and denatured Hbs in cellulo. This important observation based on NADPH consumption and increase of oxidative stress during the redox-cycling of $\mathrm{Hb}$ is expected to induce early precipitation of irreversible haemichromes and their final deposition on the RBC membrane, and, finally, to significantly enhance the phagocytic removal of ring forms in vivo (vide infra). This last event was indeed shown to occur in G6PD-deficient RBCs both in vitro and in vivo and was suggested as the possible mechanism of resistance against severe malaria observed in G6PD-deficient subjects $(4,12)$.

\section{Mechanism of action of antimalarial benzyIMDs}

The key feature of antimalarial activity of benzylMD 1c resides in the continuous NADPH-consuming redoxcycling based on the interplay between drug and $\mathrm{Hb}$ species generated in GR-catalyzed reactions and free- or bound-iron species, ultimately disturbing the redox homeostasis in the $\mathrm{pRBC}$. A direct proof that this redox-cycling occurs in situ in the parasite or any evidence of proposed metabolites is technically highly complicated, because (i) conventional approaches disrupt the sub-cellular integrity and (ii) redoxcyclers act as catalysts (i.e., in trace amount). To overcome these obstacles and uncover the role of redox-cycling of 1c in the expression of its antimalarial activity, we both performed in vitro drug interaction studies (Fig. 4) and analyzed the glutathione redox potential in the cytosol of intact living pRBCs using the recently developed genetically encoded real-time fluorescent biosensor (genetically encoded human glutaredoxin 1 fused to a redox-sensitive GFP [ $h \mathrm{Grx} 1$ roGFP2]) (Fig. 5) (31).

In vitro drug interaction studies. These experiments were conducted according to the fixed-ratio isobologram method (18). We selected three sets of compounds that affect the redox metabolism of pRBCs, either by inhibiting the GR activity, or interfering with (labile or bound) iron complexation, or playing a role in varying the NADPH/NADP ${ }^{+}$ balance in pRBCs.

In a previous work on GR inhibition, we designed the difluoromethyl analogue (P_TM101, Fig. 4a, b) of the bromo benzylMD acting as a prodrug of a suicide inhibitor of both GRs of the pRBC cytosols $(8,36)$. The loss of the antimalarial activity observed with P_TM101 alone $\left(\mathrm{IC}_{50}=13.2 \mu M\right)$ and due to GR inactivation in situ suggested that continuous and effective GR-catalyzed reduction of the redox-cycler is an essential prerequisite for the antimalarial activity of the benzylMD series (36). Thus, by combining both benzylMDs 1c and P_TM101, it was not surprising to observe an antagonist effect $\left(\sum\right.$ fractional inhibitory concentration $\left[\mathrm{FIC}_{50}\right]=$ 1.33 ), though this effect was rather weak compared to the antagonistic effects of desferrioxamine B (DFO) or epigallocatechin-3-gallate (EGCG) (vide infra).

The drug combination of the parent drug $1 \mathbf{c}$ and its putative metabolite, the benzoxanthone $\mathbf{4 c}$, was observed to have an additive effect (Fig. 4a, c). This suggests that blocking two vital and related redox processes for parasite development, that is, $\mathrm{Hb}$ oxidation (metHb formation is the first step to start $\mathrm{Hb}$ digestion) through metHb reduction and inhibition of haemozoin formation, has neutral effects on reducing the growth of malaria parasites by acting on two distinct steps of the same $\mathrm{Hb}$ digestion pathway (in a non-interfering manner), as in the additive combination of methylene blue and mefloquine (2).

Regarding iron complexation, we propose that the metalbinding properties of reduced benzylMD-derived metabolites, as in benzoylMD 3c, play a critical role in the global activity of the lead benzylMD 1c. This was evidenced by the antagonistic interaction between $1 \mathrm{c}$ and a powerful $\mathrm{Fe}^{\mathrm{III}}$ chelator from Streptomyces, DFO (Fig. 4a, b). Interestingly, the observed antagonist effect mediated by DFO on the antimalarial activity of the lead benzylMD $1 \mathbf{c}$ is the highest $\left(\sum \mathrm{FIC}_{50}=2.39\right)$ tested among all compound combinations to 1c. As suggested in our previous study, the benzoylMD 3c was proposed to cycle in and out of the acidic vesicles, upon iron complexation/release and drug oxido-reduction by GR (36). It is noteworthy to mention the strong antagonistic effect exerted by DFO with semisynthetic and synthetic endoperoxide antimalarial drugs $(52,56)$. This study suggested a 
a

\begin{tabular}{|c|c|c|c|}
\hline $\begin{array}{l}\text { "drug B" } \\
\text { tested in } \\
\text { combina- } \\
\text { tion with 1c }\end{array}$ & $\begin{array}{l}\mathrm{IC}_{50} 3 \mathrm{D} 7 \text { of } \\
\text { "drug B" alone } \\
(\mu \mathrm{M})\end{array}$ & $\begin{array}{l}\text { Sum of } \mathrm{FIC}_{50} \\
\text { values }(n)\end{array}$ & Interaction \\
\hline $1 \mathrm{c}$ & $0.07 \pm 0.02(6)$ & $0.98 \pm 0.02(3)$ & additive \\
\hline $4 c$ & $12.8 \pm 2.2(3)$ & $1.0 \pm 0.1$ & additive \\
\hline P_TM101 & $13.2 \pm 4.4(3)$ & $1.3 \pm 0.1(4)$ & $\begin{array}{l}\text { slightly } \\
\text { antagonistic }\end{array}$ \\
\hline DFO & $12.3 \pm 0.8(3)$ & $2.4 \pm 0.6(3)$ & antagonistic \\
\hline EGCG & $59.3 \pm 8.2(3)$ & $1.7 \pm 0.1$ & antagonistic \\
\hline CB83 & $14.6 \pm 0.3(2)$ & $2.3 \pm 0.6(4)$ & antagonistic \\
\hline ML276 & $1.6 \pm 0.4(3)$ & $1.0 \pm 0.1$ & additive \\
\hline
\end{tabular}

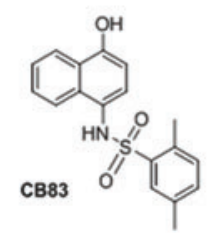

b

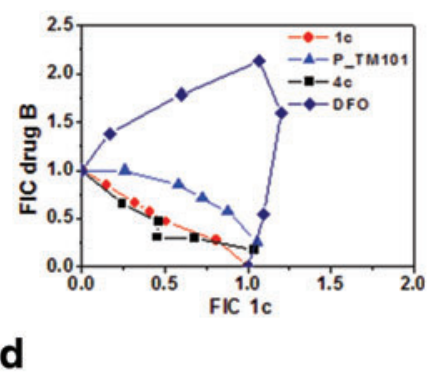

Compound tested

\begin{tabular}{llll}
\hline $\begin{array}{l}\text { Compound tested } \\
\text { in combination with } \\
\text { 1c }\end{array}$ & $\begin{array}{l}\mathrm{IC}_{50} 1 \mathrm{c} \\
3 \mathrm{D} 7(\mathrm{nM})\end{array}$ & $\begin{array}{l}\text { Mean } \mathrm{IC}_{50} \\
\text { shift }(\%)\end{array}$ & Interaction \\
\hline $\begin{array}{l}\text { No additional drug } \\
+ \text { nicotinamide } \\
(3 \mathrm{mM})\end{array}$ & $68.2 \pm 17.5(6)$ & & \\
+6 -amino- & $35.3 \pm 13.9(3)$ & -48.2 & synergistic \\
$\begin{array}{l}\text { nicotinamide } \\
(0.5 \mathrm{mM})\end{array}$ & $95.4 \pm 19.2(3)$ & +39.9 & antagonistic \\
\hline
\end{tabular}

c
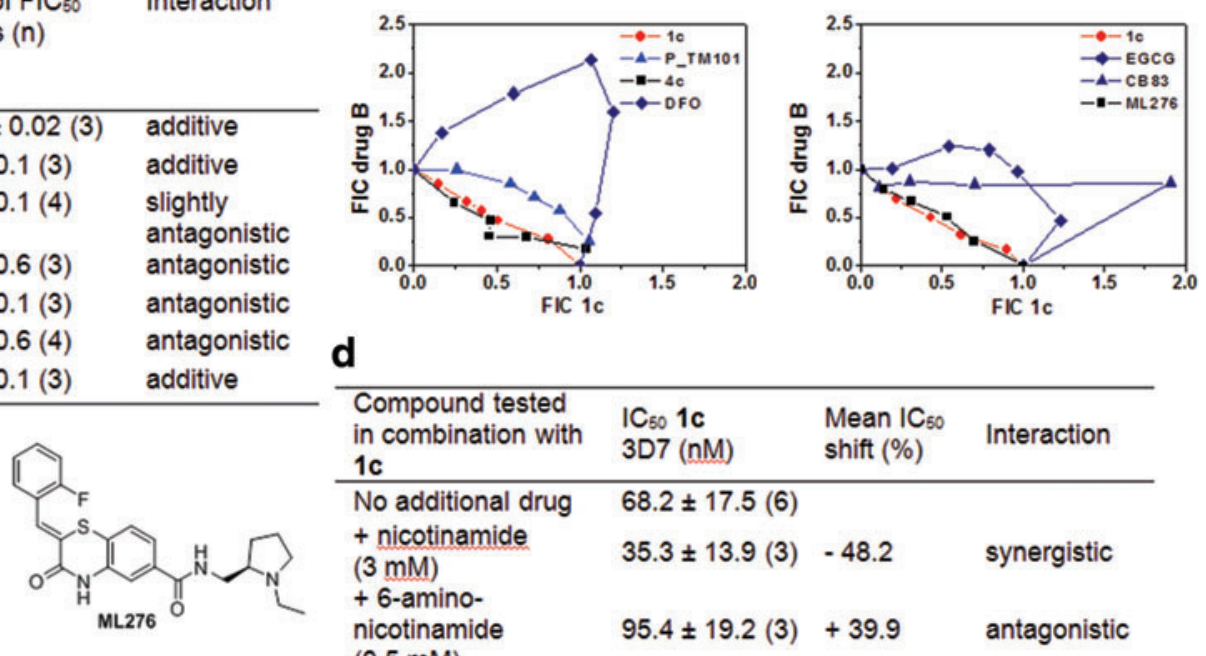

FIG. 4. In vitro interactions between the lead benzylMD 1c ("drug A") and experimental molecules ("drug B") analyzed with RBCs parasitized by $\boldsymbol{P}$. falciparum $3 \mathrm{D} 7$ strain. (a) Table with $\mathrm{IC}_{50}$ values of each drug alone and the mean $\sum$ FIC values determined by the fixed-ratio isobologram method. (b) Table with $\mathrm{IC}_{50}$ values of the lead benzylMD $1 \mathbf{c}$ alone or in the presence of a fixed dose of an additional metabolite. All data are presented as means \pm standard deviation determined from $(n)$ independent experiments. (c, d) Isoboles depicting the in vitro interactions of 1c with DFO (antagonistic), P_TM101 (antagonistic) and 4c (additive) (c) or with EGCG (antagonistic), the PfGluPho inhibitor ML276 (additive), or the $h \mathrm{G6PDH}$ inhibitor CB83 (antagonistic) (d). Interaction of 1c with itself (control assay of additivity) is shown in red. Graphs display pairs of FIC values of 1c ( $x$ axis), and the drug in combination (drug B) ( $y$ axis) in different combinations. Plots are from one representative experiment, arithmetical values from 3 to 4 independent experiments are reported in (a). DFO, desferrioxamine B; EGCG, epigallocatechin-3-gallate; FIC, fractional inhibitory concentration; $h$ G6PD, human glucose-6-phosphate dehydrogenase; PfGluPho, bifunctional enzyme from Plasmodium falciparum that combines G6PD and 6PGL. To see this illustration in color, the reader is referred to the web version of this article at www .liebertpub.com/ars

common non-haem chelatable iron-dependent activation mechanism for endoperoxide drugs via $\mathrm{Fe}^{\mathrm{III}}-\mathrm{Fe}^{\mathrm{II}}$ redox cycling. Taking into account the central role of DFO as an iron chelator in fungi, we expected that DFO might inhibit the transport of drug metabolites:iron complexes in and out of the parasite compartments, similar to microbial siderophores upon iron complexation. Furthermore, DFO is proposed to deplete iron sources that are essential for enhancing ROS generation. However, DFO was also reported to weakly interact with haem (56) and reduce ferrylHb to metHb, therefore preventing haemichrome formation (46) that might result in the strong observed antagonism effect of DFO and benzylMD 1c.

In both the parasite and RBC, G6PD, as the rate-limiting step of PPP, generates NADPH. In the parasite, NADPH is mainly produced by a bifunctional enzyme, PfGluPho, that combines G6PD and the second enzyme of the PPP, 6-phosphogluconolactonase (6PGL). PfGluPho is likely essential for the parasites' antioxidant defense and thus survival, and it differs in structure and kinetic mechanism from the human homologues G6PD and 6PGL $(29,42)$. We therefore tested ML276, a potent and highly selective PfGluPho inhibitor, on PfGluPho versus human G6PD (Fig. 4a, c) (41, 43). When combined with benzylMD 1c, we found a clear, indifferent interaction $\left(\sum \mathrm{FIC}_{50}=1.02\right)$, suggesting that both strategies aimed at disturbing NADPH formation (de novo biosynthesis and regeneration) and the redox balance in the malaria parasites involve complementary processes, opening possibilities for new drug combinations. It is noteworthy that the com- pound CB83, which was selected as an effective irreversible inhibitor of human G6PD ( $h$ G6PD), only weakly inhibits PfGluPho (41). When combined with benzylMD 1c, a strong antagonist effect $\left(\sum \mathrm{FIC}_{50}=2.3\right)$ was determined (Fig. 4a, c), possibly explained by the decreased rate of NADPH-dependent bioactivation of benzylMD 1c in the host cell. Importantly, we checked whether compound 1c and the key metabolite $2 \mathbf{c}$ tested alone in enzymic assays using the human $h$ G6PD or the plasmodial PfPhuGlo enzymes could behave as inhibitors of NADPH regeneration. The $\mathrm{IC}_{50}$ values of the compounds on both enzymes were determined to be $c a .200 \mu M$, and the assay started becoming turbid at these high concentrations. So, a biologically relevant inhibition of both enzymes might be excluded.

We also tested the major constituent of green tea polyphenols, EGCG, known as an unspecific inhibitor of $h$ G6PD and other enzymes that employ $\mathrm{NADP}^{+}$as a coenzyme to regenerate NADPH (49). As for CB83, a clear antagonist effect $\left(\sum \mathrm{FIC}_{50}=1.7\right)$ was observed when used in combination with the lead benzylMD 1c (Fig. 4a, c). It is now recognized that even in G6PD-deficient RBCs with $1-5 \%$ of normal G6PD activity, invasion and development of the parasite assessed during two growth cycles were not altered (12). However, the rapidly growing parasite needs NADPH for biosynthetic processes and rapidly develops its own G6PD and oxidative portion of PPP independently from the host RBC.

The possibility that other de novo NADPH biosynthesis pathways are expressed in the parasites has not been fully 


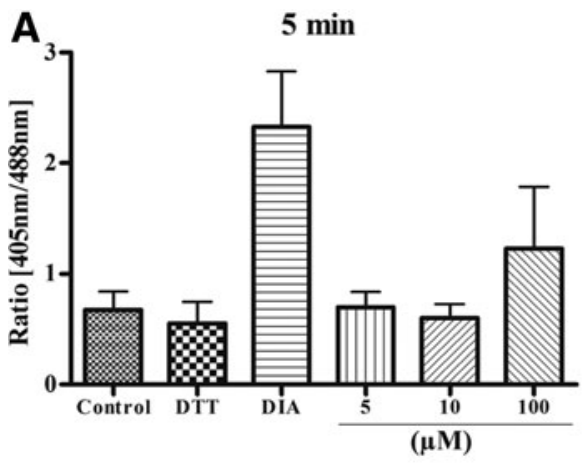

C in the $\left[{ }^{3} \mathrm{H}\right]$ hypoxanthine incorporation assay. The effect of benzylMD 1c at different concentrations on the glutathione-dependent redox potential of the cytosol was investigated by the ratiometric measurement of fluorescence intensities after excitation at 405 and $488 \mathrm{~nm}$. Each data point represents 10-20 trophozoites. Treatment with $1 \mathrm{~m} M$ diamide was carried out to achieve maximal oxidation and $10 \mathrm{~m} M$ DTT to obtain full reduction. After incubation of (A, B) 5 min, (C, D) 4 h, or (E, F) $24 \mathrm{~h}$ the cytosolic redox state was clamped by $20 \mathrm{mM}$ $N$-ethylmaleimide and images were taken by CLSM. CLSM, confocal laser-scanning microscopy; DTT, dithiothreitol.
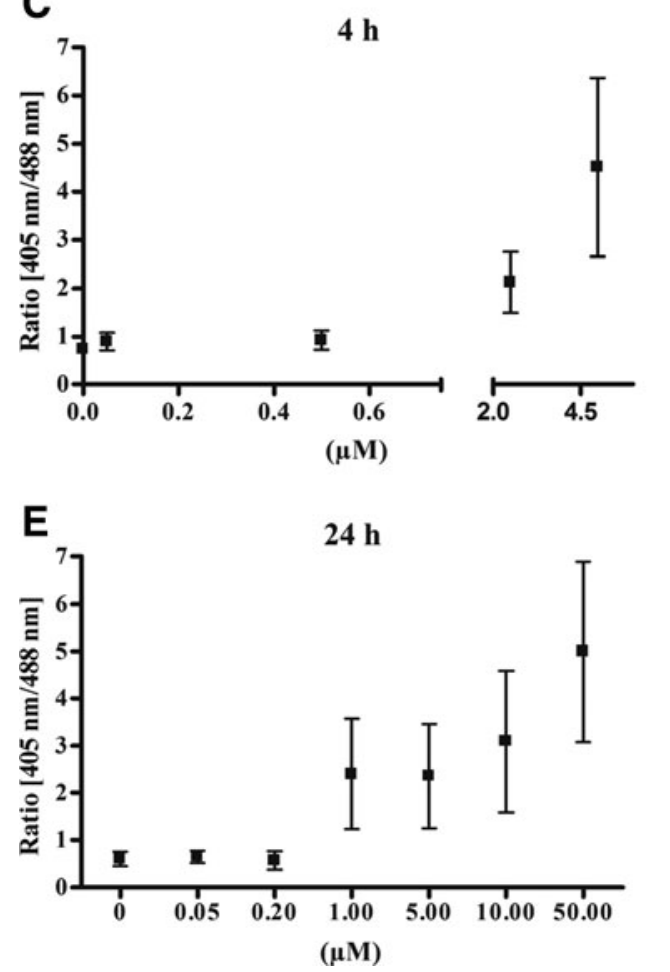

B

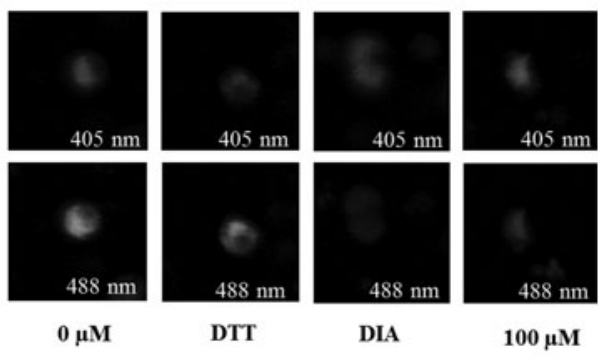

D

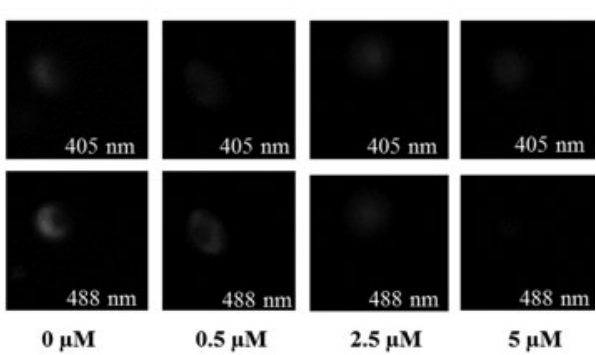

$\mathbf{F}$



explored (59). In higher eukaryotes, two major biochemical pathways, the salvage and the de novo pathway, are involved in the biosynthesis of $\mathrm{NAD}^{+}$. In human cells, the salvage pathway operates via two major pathways through the nicotinamide phosphoryltransferase and nicotinamide phosphoribosyltransferase 1, which use nicotinamide and nicotinic acid, respectively, as substrates for $\mathrm{NAD}^{+}$recycling $(15,27)$. While nicotinamide is apparently not utilized in the normal RBC for NAD-NADP synthesis, it is consumed by the pRBC, accounting for an observed 10-fold increase in NAD level in pRBCs (59). We determined the $\mathrm{IC}_{50}$ value of the lead drug $\mathbf{1 c}$ in the presence of a fixed sublethal dose of nicotinamide $(3 \mathrm{mM})$ using $P$. falciparum strain 3D7 pRBCs. A ca. 50\%-decreased $\mathrm{IC}_{50}$ value for benzylMD 1c was found, suggesting a promising synergistic effect of nicotinamide and the lead benzylMD 1c (Fig. 4d). The effect was counteracted by the antimetabolite 6-aminonicotinamide ( $c a .40 \%$-increased $\mathrm{IC}_{50}$ value).

This important finding holds promise for the development of antimalarial drug combination therapies based on NADPH-consuming bioactivation. Nicotinamide $(20 \mathrm{mM})$ has been shown to significantly delay parasite growth in culture and to inhibit the histone deacetylase (HDAC) ac- tivity of PfSir2. This member of class III HDACs was recently identified as essential for epigenetic regulation of virulence genes central to malaria pathogenesis (44). Such combined synergistic/additive effects displayed by benzylMD 1c and the agents affecting the NADPH flux in vivo (nicotinamide or PfGluPho inhibitor) might provide opportunities to treat artemisinin-resistant parasites and could prevent resistance mechanisms or metabolic adaptations.

Effect of benzyIMD 1c on the glutathione redox potential of intact living Plasmodium falciparum 3D7. Recently, $h$ Grx 1roGFP2 was described as a suitable luminescent biosensor of the glutathione-dependent redox potential in the blood stages of P. falciparum (31). The sensor consists of human glutaredoxin 1 ( $h \mathrm{Grx} 1)$ fused to a redox-sensitive GFP (roGFP). Upon oxidation, the formation of a disulfide bridge in the sensor leads to shifts in the fluorescence intensities excited at 405 and $488 \mathrm{~nm}$, which enables analysis of changes in the ratio of oxidized and reduced glutathione (26).

To study the effects of the redox-active benzylMD 1c on the glutathione-dependent redox ratio of the cytosol in P. falciparum 3D7, we examined its short, medium, and 
long-term effects on living parasites transfected with the redox probe via confocal laser-scanning microscopy (CLSM; see below). Control experiments (Supplementary Fig. S10a-f) indicated that a direct interaction between benzylMD 1c and the recombinant redox sensor at pharmacologically relevant concentrations that might influence the results can be excluded. Parasites transfected with the $h$ Grx1-roGFP2 redox probe were synchronized to the trophozoite stage, incubated for various time periods with benzylMD 1c at different concentrations, and studied via CLSM (Fig. 5).

Short-term incubation ( $5 \mathrm{~min}$ ) only showed effects on the redox ratio at concentrations of benzylMD $1 \mathbf{c} \geq 100 \mu \mathrm{M}$ $\left(2000 \times \mathrm{IC}_{50}\right)($ Fig. $5 \mathrm{~A}, \mathrm{~B})$. The effects of higher benzylMD 1c concentrations could not be studied because of strong oversaturation during CLSM. After a $4 \mathrm{~h}$ incubation, significant $405 / 488 \mathrm{~nm}$ ratio changes were observed at lower concentrations: $0.76 \rightarrow 0.91$ at $0.5 \mu M\left(10 \times \mathrm{IC}_{50}\right) ; 0.76 \rightarrow 2.1$ (2.8-fold change) at $2.5 \mu M\left(50 \times \mathrm{IC}_{50}\right)$; and $0.76 \rightarrow 4.48$ (5.9fold change) at $5 \mu M\left(100 \times \mathrm{IC}_{50}\right)$, indicating a decrease in the GSH:GSSG ratio and therefore a shift towards a more oxidizing glutathione redox potential in the cytosol (Fig. $5 \mathrm{C}, \mathrm{D})$. After a $24 \mathrm{~h}$ incubation, effects on the glutathionedependent redox ratio (Fig. 5E, F) were observed at benzylMD 1c concentrations $\geq 1 \mu M$. As indicated by the $4 \mathrm{~h}$ data, benzylMD 1c seems to influence the cytosolic redox potential in a way similar to other antimalarial drugs, including quinine, $\mathrm{CQ}$, and artemisinin, which lead to ratio changes after a $4 \mathrm{~h}$ incubation at concentrations of about $20 \times \mathrm{IC}_{50}$ (31). However, benzylMD 1c seems to act more rapidly, shifting the GSH:GSSG equilibrium toward GSSG and having shorter-term effects on glutathione redox potential compared to artemisinin and quinolone (31).

Haemichrome formation and increased phagocytosis induced by lead benzyIMD 1c specifically occurs in ringparasitized RBCs and not in non-parasitized RBCs. RBC destruction due to unbalanced oxidative stress, largely occurring via extravascular phagocytosis, is mechanistically identical in normal RBC senescence and pathological haemolysis $(5,32,40)$. In sequence, an excess of oxidative stress generates haemichromes that bind to band 3 , inducing band 3 clustering, deposition of opsonins, and enhancement of RBC phagocytosis $(5,32,40)$. The above sequence of oxidative events can be reproduced and assayed in vitro using isolated phagocytes or phagocytic cell lines $(5,21)$. G6PD-deficient RBCs [and the phenotypically identical GR-deficient RBCs (20)], are unable to regenerate $\mathrm{GSH}$, the powerful oxidative radical scavenger, and are more susceptible to oxidative stress, haemichrome deposition, and phagocytosis $(3,4,39,40)$.

Several case-controlled studies performed in Africa and South-East Asia have shown the protective role of G6PD deficiency against falciparum malaria $(13,25,34,35,53)$. The protective effect is not due to impaired invasion or maturation of the parasite, but is considered to result from enhanced phagocytosis of ring stages $(12,58)$. Ring-stage parasitized normal RBCs are neither oxidatively damaged nor removed via phagocytosis $(12,22,54)$. By contrast, ringparasitized G6PD-deficient RBCs are particularly vulnerable to oxidative stress $(6,12)$, intensely phagocytosed because of the low activity of the host's parasites' G6PD, and unable to counteract membrane damage and opsonin deposition $(4,12)$. Early field studies have confirmed that preferential ring phagocytosis described in vitro (12) is indeed occurring in vivo in G6PD-deficient malaria patients (34). Of note, other widespread RBC mutations characterized by high endogenous oxidative stress such as the thalassemias and sickle-cell trait also protect against severe malaria $(24,58)$. Similar to G6PD deficiency, protection was suggested to derive from accelerated removal of ring pRBCs, observed both in vitro (7) and in vivo $(24,33)$.

Similar to the mechanism of malaria resistance in G6PDdeficient individuals outlined earlier $(12,58)$, here, benzylMD drugs were shown to enhance oxidative damage, haemichrome formation, and phagocytic removal, specifically in ringpRBCs (schematized in Fig. 6a). To quantify not only benzylMD 1c-induced membrane-bound haemichrome formation in pRBCs exclusively but also the safety of lead benzylMD 1c on non-parasitized G6PD-deficient RBCs, we investigated the response in RBCs with normal and deficient G6PD (Figs. $6 \mathrm{~b}$ and $6 \mathrm{c}$, respectively) to treatment by benzylMD 1c. As shown in Figure 6b, there was no appreciable formation of haemichromes in non-parasitized normal RBCs treated during the $4 \mathrm{~h}$ until 100 -fold $\mathrm{IC}_{50}$ concentration of the benzylMD 1c. A distinct, significant increase of haemichromes was noted in the positive controls treated with $2 \mathrm{~m} M$ phenylhydrazine $(\mathrm{PH})$. By contrast, treatment with benzylMD 1c at 10to 100 -fold the $\mathrm{IC}_{50}$ concentration strongly and significantly enhanced haemichrome formation in only ring-pRBCs.

Furthermore, experiments were also performed with $\mathrm{pRBC}$ and non-parasitized G6PD-deficient RBCs (Mediterranean variant with $<1 \%$ normal enzyme activity) characterized by high sensitivity toward $\mathrm{PH}$ and oxidant like diamide. Results shown in Figure $6 \mathrm{c}$ indicate that both 4 and $8 \mathrm{~h}$ incubation of non-parasitized G6PD-deficient RBCs with lead benzylMD 1c up to 100 -fold the $\mathrm{IC}_{50}$ concentration did not produce any haemichrome. By contrast, non-parasitized G6PD-deficient $\mathrm{RBC}$ s treated with $2 \mathrm{~m} M$ diamide or $\mathrm{PH}$ produced high levels of haemichromes after $4 \mathrm{~h}$ of drug treatment. In further experiments, we also evaluated whether benzylMD-treated ring-pRBCs were removed more intensely by a human phagocytic cell line compared to control untreated ring-pRBCs or control non-parasitized cells. As shown in Figure 6d, treatment with benzylMD 1c at 100 -fold the $\mathrm{IC}_{50}$ significantly increased in vitro phagocytosis of ring-pRBCs compared to benzylMD 1c-treated non-parasitized control RBCs $(p=0.001)$. Phagocytosis of benzylMD 1c-treated ring-pRBCs was also significantly higher compared to untreated ring-pRBCs $(p=0.02)$.

Thus, the antimalarial benzylMD 1c is the first example of a novel agent that exerts its potent antimalarial activity by mimicking the mechanism of protective effects of G6PD deficiency, and it induces its toxic effects in pRBC specifically without harming non-infected G6PD-sufficient or -deficient RBCs.

\section{Discussion \\ Importance of the interplay between drug metabolites and haemoglobin catabolites for maintaining the NADPH-dependent cascade of redox reactions}

In this work, we have shown that the metabolites of the potent antimalarial benzylMD 1c, the benzoylMDs 2c, 3c, and the benzoxanthone $\mathbf{4} \mathbf{c}$ interact at various stages of the redox machinery of $P$. falciparum $\mathrm{pRBCs}$, which could explain the potent antimalarial activity of the lead agent 1c. In 

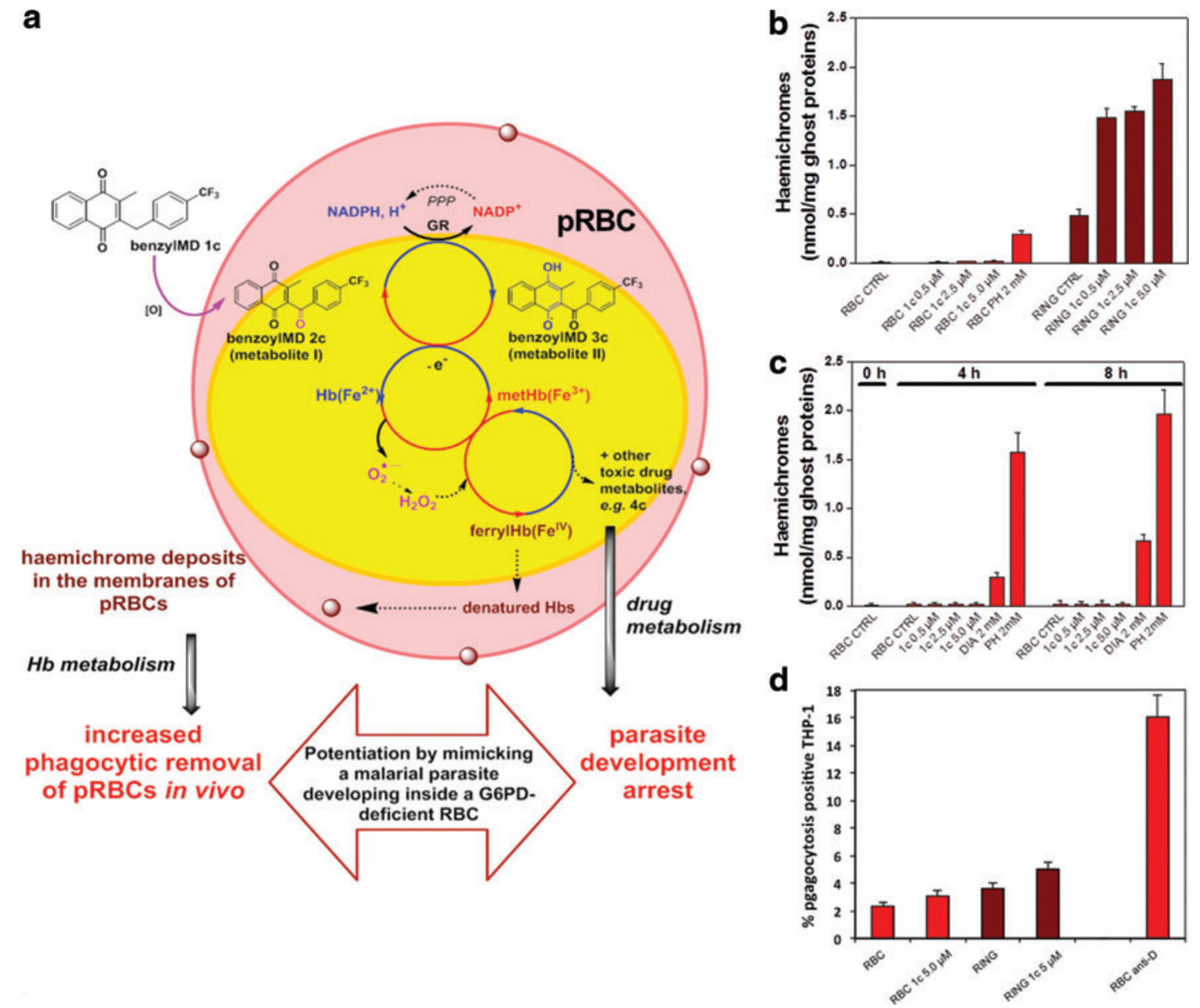

FIG. 6. Potentiation of resistance of parasitized RBCs against malaria development: consequences of both drug metabolism and haemoglobin catabolism on (i) membrane-bound haemichromes in ring-pRBC versus non-parasitized G6PD-normal and non-parasitized G6PD-deficient RBCs, (ii) on phagocytosis by THP-1 cells of benzylMD 1ctreated or untreated ring-parasitized RBCs and non-parasitized RBCs. (a) Schematic figure of a pRBC treated by the benzylMD 1c: the lead drug is internalized in a pRBC and oxidized into the key metabolite, the benzoylMD 2c, which is reduced in a GR-catalyzed reaction in the cytosols of parasitized cells. The reduced benzoylMD 3c reduced metHb into Hb in a continuous NADPH-consuming redox cycle ending in ferrylHb formation and membrane-bound haemichromes. The benzylMD 1c at different concentrations was studied for its effects on G6PD-normal non-parasitized or ring-pRBCs. (b) Membrane-bound haemichromes in G6PD-normal non-parasitized RBCs (red bars), and ring-pRBCs (RING, wine bars) treated or not (CTRL) with the benzylMD 1c at $0.5 \mu M\left(10\right.$-fold $\left.\mathrm{IC}_{50}\right), 2.5 \mu M$ (50-fold $\left.\mathrm{IC}_{50}\right), 5.0 \mu M\left(100\right.$-fold $\left.\mathrm{IC}_{50}\right)$, or $2.0 \mathrm{~m} M \mathrm{PH}$, and incubated for $4 \mathrm{~h}$ at $37^{\circ} \mathrm{C}$. Haemichromes are expressed as nmol $/ \mathrm{mg}$ ghost protein; mean values $\pm \mathrm{SD}, n=2-$ 4. Haemichromes were significantly higher $(p<0.001)$ in treated ring-pRBCs compared with untreated ring-pRBCs and non-parasitized treated and untreated controls. (c) G6PD-deficient RBCs (hemizygous males, Mediterranean variant, G6PD activity $<1 \%$ of normal enzyme). Membrane-bound haemichromes in non-parasitized G6PD-deficient RBCs, incubated during 4 and $8 \mathrm{~h}$ at $37^{\circ} \mathrm{C}$ without (CTRL) or with the benzylMD 1c at $0.5 \mu M$ (10-fold $\left.\mathrm{IC}_{50}\right), 2.5 \mu M\left(50\right.$-fold $\left.\mathrm{IC}_{50}\right), 5.0 \mu M$ $\left(100\right.$-fold $\left.\mathrm{IC}_{50}\right), 2.0 \mathrm{~m} M$ DIA, or $2.0 \mathrm{~m} M \mathrm{PH}$. Haemichromes are expressed as $\mathrm{nmol} / \mathrm{mg}$ ghost protein. Mean values of normal controls (mean $\pm \mathrm{SD}, n=2-4)$ are shown. Haemichromes were significantly higher $(p<0.001)$ in DIA- and PHtreated G6PD-deficient RBCs compared to untreated controls. (d) Phagocytosis of ring-enriched pRBCs and non-parasitized RBCs treated or not with benzylMD $1 \mathrm{c}$ by THP-1 cells. After a $3 \mathrm{~h}$ incubation with benzylMD $1 \mathrm{c}$ at $5 \mu M\left(100-\right.$ fold IC $\left._{50}\right)$ in a humidified $\mathrm{CO}_{2}$ /air incubator, the cells (ring-enriched pRBCs [17-20\% synchronized early rings enriched at 16-18 $\mathrm{h}$ after re-infection] and non-parasitized RBCs, treated or not with benzylMD 1c) were washed, opsonized with heterologous serum $(0+$ group $)$, and labeled with CFDA-SE (Sigma). CFDA-SE is a non-fluorescent lipophilic molecule that passively diffuses into the cell, where it is activated by esterase cleavage of its acetyl groups to the brightly fluorescent derivative CF-SE. CF$\mathrm{SE}$ is a non-toxic molecule stably retained in the cell; it emits stable and homogeneous fluorescence and does not interfere with RBC functionality. THP-1 cells pre-stimulated during a $24 \mathrm{~h}$ incubation with tumor necrosis factor (250 U/ml) and interferon-gamma $(50 \mathrm{U} / \mathrm{ml})$ to enhance their phagocytic activity (21) were incubated with target RBCs for phagocytosis assay. After $2.5 \mathrm{~h}$ phagocytosis in a humidified $\mathrm{CO}_{2}$ /air incubator, THP-1 cells were separated from non-phagocytosed RBCs and analyzed via flow cytometry. Opsonization with anti D-IgG was used as a positive phagocytosis control. Phagocytosis was expressed as a percentage of phagocytosis-positive THP-1 cells (mean values $\pm \mathrm{SD}, n=4$ ). Phagocytosis of benzylMD 1c-treated ring-pRBC was significantly higher compared to phagocytosis of untreated ring-pRBCs $(p=0.02)$ or benzylMD 1c-treated non-parasitized RBCs. $(p=0.001)$. Increased phagocytosis of non-parasitized RBCs pre-treated with benzylMD 1c versus untreated non-parasitized RBCs was not significant. CFDA-SE, 5(6)-carboxyfluorescein diacetate $N$-succinimidyl ester; CTRL, drug-untreated control; DIA, diamide; PH, phenylhydrazine. To see this illustration in color, the reader is referred to the web version of this article at www.liebertpub.com/ars 
its reduced state, benzoylMD $3 c$ reduces metHb and ferriprotoporphyrin IX or haem to indigestible $\mathrm{Hb}$ and toxic ferrous protoporphyrin IX, respectively, thereby inhibiting haemozoin formation. In its oxidized state, the benzoylMD 2c acts as substrate of both $h \mathrm{GR}$ and $P f \mathrm{GR}$, depleting the cell reductant NADPH. Due to this process, the antioxidant thiol network of the parasite cannot be maintained. The continuous generation of ROS causes immense oxidative stress in the cells, which results in denaturation and precipitation of $\mathrm{Hbs}$. The consequence was an increased generation of intracellular ROS in early parasite stages that die rapidly, the irreversible oxidation of the glutathione system, and the formation of membrane-associated haemichromes in ring-pRBCs. The disturbance of redox equilibrium generates a hostile milieu for parasite development, which is known to accelerate the senescence of the RBCs and, finally, their phagocytosis in vivo. Interestingly, the benzylMD 1c was shown here to be totally ineffective in producing haemichrome deposition when added to non-parasitized G6PD-deficient RBCs.

Furthermore, several drugs altering redox homeostasis in pRBC were considered and shown to antagonize the benzylMD 1c effects at different levels and to a varying extent, as illustrated with suicide inhibitors of the GR activity (P_TM101), with compounds interfering with labile or bound iron complexation (DFO), or with inhibitors of the machinery responsible for maintaining NADPH/NADP ${ }^{+}$balance in pRBCs (both $h \mathrm{G} 6 \mathrm{PD}$ inhibitors: CB83, EGCG). While the antagonism exerted by P_TM101 was rather weak compared to DFO or EGCG effects, this observation allowed us to speculate on the presence of another NADPH-dependent flavoenzyme, which could also partially bioactivate the benzylMD 1c when GR has been irreversibly inactivated by P_TM101. Regarding the strongest antagonistic effect observed on DFO and benzylMD 1c combination, this result suggests that DFO could counteract benzylMD 1c action either (i) by chelating the free $\mathrm{Fe}^{\mathrm{III}}$ essential for drug trafficking within the different compartments of the parasite, or (ii) by decreasing the oxidative stress induced by free iron (Fenton reaction) in accordance with the antioxidant effect of DFO versus the prooxidant effect of the redox-cyclers, or (iii) more likely by preventing the benzoylMD $2 \mathbf{c}$-induced haemichrome formation from ferrylHb, as previously reported for DFO-treated erythrocytes (46).

Thus, taken together, this work suggests a novel antimalarial drug mechanism based on the specific acceleration of the formation of ROS, and membrane-associated haemichromes in benzylMD 1c-treated ring-pRBCs, through a dynamic interplay between drug metabolites and haemoglobin catabolites. This hypothesis is supported by in cellulo data obtained with isolated reconstructed systems as well as by in vitro data from an isolated phagocytic cell line.

\section{BenzyIMD 1c-treated ring-pRBCs are "copycats" of malaria-protected G6PD-deficient ring-pRBCs- mimicry with malaria resistance afforded by G6PD deficiency}

The benzylMD 1c appears to exert its antiplasmodial activity by mimicking a falciparum parasite developing inside a G6PD-deficient RBC. Thus, enhanced phagocytosis of ring-pRBCs is advantageous to malaria patients. First, removal of rings means reduction in parasitaemia; second, phagocytosed rings are digested rapidly and repeatedly by phagocytes, while phagocytosis of haemozoin-containing late parasite forms impairs phagocytic efficiency and disables several functions of monocytes and macrophages (48); and third, lower numbers of late forms cytoadhere to endothelia in several organs. Cytoadhesion in vital organs appears to be the main cause of fatal malaria (51), for example, cytoadhesion in bone marrow, brain and lungs is responsible for malaria anemia (50), cerebral malaria (57), and malaria respiratory distress, respectively (55). Besides these clinical aspects, this work has also opened innovative routes for antimalarial drug design and synergistic/additive combinations, as illustrated with compounds disturbing the NADPH flux in pRBCs (PfGluPho inhibitor ML276, nicotinamide). These findings will contribute to new research directions to decipher the de novo NADPH biosynthesis pathways in malarial parasites.

\section{Materials and Methods}

All detailed experimental procedures and analyses for the preparation and characterization of the new compounds $3 \mathbf{c}^{*}$, $\mathbf{4 c}, \mathbf{5 c - i}, \mathbf{6 c - i}$, and $\mathbf{7 c - i}$ as well as spectroscopic data used in chemistry, physico- and electro chemistry, and cell biological evaluations are included as Supplementary Data.

\section{Acknowledgments}

L.J. and D.A.L. are grateful to the NIH/National Institute of Allergy and Infectious Disease (NIAID) - through the grant R01AI065622 to D.L.W.- for partial contribution to their $\mathrm{PhD}$ and post-doctoral salaries, respectively. V.G. thanks the COST Action CM0801 for the STSM fellowships that have stimulated joint discussions between Italy's groups and E.D.C.'s laboratory. The authors are grateful to Dr. Christiane Deregnaucourt from the Museum National d'Histoire Naturelle, FRE 3206 CNRS, Paris, France and Prof. Michael Lanzer for welcoming K.E. to perform the repeats of drug combination experiments. The Torino group thanks Elena Valente and Daniela Ulliers for help with the parasite cultures. This work was partly supported by the ANRémergence program (grant SCHISMAL [E.D.-C.]), the Laboratoire d'Excellence (LabEx) ParaFrap (grant LabEx ParaFrap ANR-11-LABX-0024 [E.D.C.]), the international Center for Frontier Research in Chemistry icFRC in Strasbourg (www.icfrc.fr), the NIH/National Institute of Allergy and Infectious Disease (grant R01AI065622 [D.L.W.]), the EVIMALAR (European Virtual Institute dedicated to Malaria Research), Project No. 242095, to P.A., and the Deutsche Forschungsgemeinschaft (BE1540/ 11-2 to K.B. and JO1085/1-2 [E.J.]).

\section{Author Disclosure Statement}

No competing financial interests exist.

\section{References}

1. Aguilar-Martínez M, Macías-Ruvalcaba NA, BautistaMartínez JA, Gómez M, González FJ, and González I. Hydrogen bond and protonation as modifying factors of the quinone reactivity. Curr Org Chem 8: 1721-1738, 2004.

2. Akoachere M, Buchholz K, Fischer E, Burhenne J, Haefeli WE, Schirmer RH, and Becker K. In vitro assessment of methylene blue on chloroquine-sensitive and -resistant Plasmodium falciparum strains reveals synergistic action 
with artemisinins. Antimicrob Agents Chemother 49: 45924597, 2005.

3. Arese P and De Flora A. Pathophysiology of hemolysis in glucose-6-phosphate dehydrogenase deficiency. Semin Hematol 27: 1-40, 1990.

4. Arese P, Gallo V, Pantaleo A, and Turrini F. Life and death of glucose-6-phosphate dehydrogenase (G6PD) deficient erythrocytes-role of redox stress and band 3 modifications. Transfus Med Hemother 39: 328-334, 2012.

5. Arese P, Turrini F, and Schwarzer E. Band 3/complementmediated recognition and removal of normally senescent and pathological human erythrocytes. Cell Physiol Biochem 16: 133-146, 2005.

6. Ayi K, Cappadoro M, Branca M, Turrini F, and Arese P. Plasmodium falciparum glutathione metabolism and growth are independent of glutathione system of host erythrocyte. FEBS Lett 424: 257-261, 1998.

7. Ayi K, Turrini F, Piga A, and Arese P. Enhanced phagocytosis of ring-parasitized mutant erythrocytes: a common mechanism that may explain protection against falciparum malaria in sickle trait and $\beta$-thalassemia trait. Blood 104: 3364-3371, 2004.

8. Bauer H, Fritz-Wolf K, Winzer A, Kühner S, Little S, Yardley V, Vezin H, Palfey B, Schirmer H, and DavioudCharvet E. A fluoro analogue of the menadione derivative 6-[2'(3'-methyl)-1',4'-naphthoquinolyl] hexanoic acid is a suicide substrate of glutathione reductase. Crystal structure of the alkylated human enzyme. J Am Chem Soc 128: 10784-10794, 2006.

9. Beutler E. Energy metabolism and maintenance of erythrocytes. In: Williams Hematology, 6th edn., edited by Beutler E, Lichtman MA, Coller BS, Kipps TJ, and Seligsohn U. New York: McGraw-Hill, 2001, pp. 319-332.

10. Biot C, Bauer H, Schirmer RH, and Davioud-Charvet E. 5Substituted tetrazoles as bioisosters of carboxylic acids. Bioisosterism and mechanistic studies on glutathione reductase inhibitors as antimalarials. J Med Chem 47: 59725983, 2004.

11. Blank O, Davioud-Charvet E, and Elhabiri M. Interactions of the antimalarial drug methylene blue with methemoglobin and heme targets in Plasmodium falciparum: a physico-biochemical study. Antioxid Redox Signal 17: 544554, 2012.

12. Cappadoro M, Giribaldi G, O’Brien E, Turrini F, Mannu F, Ulliers D, Simula G, Luzzatto L, and Arese P. Early phagocytosis of glucose-6-phosphate dehydrogenase (G6PD)-deficient erythrocytes parasitized by Plasmodium falciparum may explain malaria protection in G6PD deficiency. Blood 92: 2527-2534, 1998.

13. Cappellini MD and Fiorelli G. Glucose-6-phosphate dehydrogenase deficiency. Lancet 371: 64-74, 2008.

14. Cappellini MD, Tavazzi D, Duca L, Graziadei G, Mannu F, Turrini F, Arese P, and Fiorelli G. Metabolic indicators of oxidative stress correlate with haemichrome attachment to membrane, band 3 aggregation and erythrophagocytosis in $\beta$-thalassaemia intermedia. Br J Haematol 104: 504-512, 1999.

15. Cerna D, Li H, Flaherty S, Takebe N, Coleman CN, and Yoo SS. Inhibition of nicotinamide phosphoribosyl transferase (NAMPT) activity by small molecule GMX1778 regulates reactive oxygen species (ROS)-mediated cytotoxicity in a p53- and nicotinic acid phosphoribosyltransferase 1 (NAPRT1)-dependent manner. J Biol Chem 287: 22408-22417, 2012.

16. Cyrklaff M, Sanchez CP, Kilian N, Bisseye C, Simpore J, Frischknecht F, and Lanzer M. Hemoglobins S and C in- terfere with actin remodeling in Plasmodium falciparuminfected erythrocytes. Science 334: 1283-1286, 2011.

17. Ehrhardt K, Davioud-Charvet E, Ke H, Vaidya A, Lanzer M, and Deponte M. The mitochondrial electron transport chain is dispensable for the antimalarial activities of methylene blue and the lead 1,4-naphthoquinone 2-[4(trifluoromethyl)benzyl]-menadione. Antimicrob Agents Chemother 57: 2114-2120, 2013.

18. Fivelman QL, Adagu IS, and Warhurst DC. Modified fixedratio isobologram method for studying in vitro interactions between atovaquone and proguanil or dihydroartemisinin against drug-resistant strains of Plasmodium falciparum. Antimicrob Agents Chemother 48: 4097-4102, 2004.

19. Friebolin W, Jannack B, Wenzel N, Furrer J, Oeser T, Sanchez CP, Lanzer M, Yardley V, Becker K, and Davioud-Charvet E. J Med Chem 51: 1260-1277, 2008.

20. Gallo V, Schwarzer E, Rahlfs S, Schirmer RH, van Zwieten $\mathrm{R}$, Roos D, Arese P, and Becker K. Inherited glutathione reductase deficiency and Plasmodium falciparum malariaa case study. PLoS One 4: e7303, 2009.

21. Gallo V, Skorokhod OA, Schwarzer E, and Arese P. Simultaneous determination of phagocytosis of Plasmodium falciparum-parasitized and non-parasitized red blood cells by flow cytometry. Malar J 11: 428, 2012.

22. Giribaldi G, Ulliers D, Mannu F, Arese P, and Turrini F. Growth of Plasmodium falciparum induces stage-dependent haemichrome formation, oxidative aggregation of band 3, membrane deposition of complement and antibodies, and phagocytosis of parasitized erythrocytes. $\mathrm{Br} \mathrm{J}$ Haematol 113: 492-499, 2001.

23. Giulivi $\mathrm{C}$ and Davies KJ. A novel antioxidant role for hemoglobin. J Biol Chem 265: 19453-19460, 1990.

24. Gong L, Parikh S, Rosenthal PJ, and Greenhouse B. Biochemical and immunological mechanisms by which sickle cell trait protects against malaria. Malar J 12: 317, 2013.

25. Greene LS. G6PD deficiency as protection against falciparum malaria: an epidemiologic critique of population and experimental studies. Yearb Phys Anthropol 36: 153-178, 1993.

26. Gutsher M, Pauleau AL, Marty L, Brach T, Wabnitz GH, Samstag Y, Meyer AJ, and Dick TP. Real-time imaging of the intracellular glutathione redox potential. Nat Methods 5: 553-559, 2008.

27. Hara N, Yamada K, Shibata T, Osago H, Hashimoto T, and Tsuchiya M. Elevation of cellular NAD levels by nicotinic acid and involvement of nicotinic acid phosphoribosyltransferase in human cells. J Biol Chem 282: 24574-24582, 2007.

28. Johann L, Lanfranchi DA, Davioud-Charvet E, and Elhabiri M. A physico-biochemical study on potential redox-cyclers as antimalarial and anti-schistosomal drugs. Curr Pharm Des 18: 3539-3566, 2012.

29. Jortzik E, Mailu BM, Preuss J, Fischer M, Bode L, Rahlfs S, and Becker K. Glucose-6-phosphate dehydrogenase 6phosphogluconolactonase: a unique bifunctional enzyme from Plasmodium falciparum. Biochem J 436: 641-650, 2011.

30. Kanias $\mathrm{T}$ and Acker JP. Biopreservation of red blood cells - the struggle with hemoglobin oxidation. FEBS $J$ 277: 343-356, 2010.

31. Kasozi D, Mohring F, Rahlfs S, Meyer AJ, and Becker K. Real-time imaging of the intracellular glutathione redox potential in malaria parasite. Plos Pathog 9: e1003782, 2013.

32. Lutz HU and Bogdanova A. Mechanisms tagging senescent red blood cells for clearance in healthy humans. Front Physiol 4: e387, 2013. 
33. Luzzatto L, Nwachuku-Jarrett ES, and Reddy S. Increased sickling of parasitised erythrocytes as mechanism of resistance against malaria in the sickle-cell trait, Lancet 1: 319-322, 1970.

34. Luzzatto L, Usanga FA, and Reddy S. Glucose-6-phosphate dehydrogenase deficient red cells: resistance to infection by malarial parasites. Science 164: 839-842, 1969.

35. Mehta A, Mason, PJ, and Vulliamy TJ. Glucose-6-phosphate dehydrogenase deficiency. Baillieres Best Pract Res Clin Haematol 13: 21-38, 2000.

36. Müller T, Johann L, Jannack B, Brückner M, Lanfranchi DA, Bauer H, Sanchez C, Yardley V, Deregnaucourt C, Schrével J, Lanzer M, Schirmer RH, and Davioud-Charvet E. Glutathione reductase-catalysed cascade of redox reactions to bioactivate potent antimalarial 1,4-naphthoquinones - a new strategy to combat malarial parasites. J Am Chem soc 133: 11557-11571, 2011.

37. Muñoz-Durango K, Maciuk A, Harfouche A, Torijano-Gutiérrez S, Jullian JC, Quintin J, Spelman K, Mouray E, Grellier P, and Figadère B. Detection, characterization, and screening of heme-binding molecules by mass spectrometry for malaria drug discovery. Anal Chem 84: 3324-3329, 2012.

38. Nkhoma ET, Poole C, Vannappagari V, Hall SA, and Beutler E. The global prevalence of glucose-6-phosphate dehydrogenase deficiency: a systematic review and metaanalysis. Blood Cells Mol Dis 42: 267-278, 2009.

39. Pantaleo A, Ferru E, Giribaldi G, Mannu F, Carta F, Matte A, de Franceschi L, and Turrini F. Oxidized and poorly glycosylated band 3 is selectively phosphorylated by Syk kinase to form large membrane clusters in normal and G6PD-deficient red blood cells. Biochem J 418: 359-367, 2009.

40. Pantaleo A, Giribaldi G, Mannu F, Arese P, and Turrini F. Naturally occurring anti-band 3 antibodies and red blood cell removal under physiological and pathological conditions. Autoimmun Rev 7: 457-462, 2008.

41. Preuss J, Hedrick M, Sergienko E, Pinkerton A, Mangravita-Novo A, Smith L, Marx C, Fischer E, Jortzik E, Rahlfs S, Becker K, and Bode L. High-throughput screening for small molecule inhibitors of Plasmodium falciparum glucose-6-phosphate dehydrogenase 6-phosphogluconolactonase. J Biomol Screen 17: 738-751, 2012.

42. Preuss J, Jortzik E, and Becker K. Glucose-6-phosphate metabolism in Plasmodium falciparum. IUBMB Life 64: 603-611, 2012.

43. Preuss J, Maloney P, Peddibhotla S, Hedrick MP, Hershberger P, Gosalia P, Milewski M, Li YL, Sugarman E, Hood B, Suyama E, Nguyen K, Vasile S, Sergienko E, Mangravita-Novo A, Vicchiarelli M, McAnally D, Smith LH, Roth GP, Diwan J, Chung TD, Jortzik E, Rahlfs S, Becker K, Pinkerton AB, and Bode L. Discovery of a Plasmodium falciparum glucose-6-phosphate dehydrogenase 6-phosphoglucono lactonase inhibitor (R,Z)-N-((1-ethylpyrrolidin-2-yl) methyl)-2-(2-fluorobenzylidene)-3-oxo-3,4-dihydro-2H-benzo [b][1,4]thiazine-6-carboxamide (ML276) that reduces parasite growth in vitro. J Med Chem 55: 7262-7272, 2012.

44. Prusty D, Mehra P, Srivastava S, Shivange AV, Gupta A, Roy N, and Dhar SK. Nicotinamide inhibits Plasmodium falciparum Sir2 activity in vitro and parasite growth. FEMS Microbiol Lett 282: 266-272, 2008.

45. Reeder BJ. The redox activity of hemoglobins: from physiological functions to pathological mechanisms. Antioxid Redox Signal 13: 1087-1123, 2010.

46. Reeder BJ, Hider RC, and Wilson MT. Iron chelators can protect against oxidative stress through ferryl heme reduction. Free Radic Biol Med 44: 264-273, 2008.
47. Riscoe M, Kelly JX, and Winter R. Xanthones as antimalarial agents: discovery, mode of action, and optimization. Curr Med Chem 12: 2539-2549, 2005.

48. Schwarzer E, Skorokhod OA, Barrera V, and Arese P. Hemozoin and the human monocyte-a brief review of their interactions. Parassitologia 50: 143-145, 2008.

49. Shin ES, Park J, Shin JM, Cho D, Cho SY, Shin DW, Ham $\mathrm{M}$, Kim JB, and Lee TR. Catechin gallates are NADP ${ }^{+}$ competitive inhibitors of glucose-6-phosphate dehydrogenase and other enzymes that employ $\mathrm{NADP}^{+}$as a coenzyme. Bioorg Med Chem 16: 3580-3586, 2008.

50. Skorokhod OA, Caione L, Marrocco T, Migliardi G, Barrera V, Arese P, Piacibello W, and Schwarzer E. Inhibition of erythropoiesis in malaria anemia: role of hemozoin and hemozoin-generated 4-hydroxynonenal. Blood 116: 43284337, 2010.

51. Smith JD, Rowe JA, Higgins MK, and Lavstsen $T$. Malaria's deadly grip: cytoadhesion of Plasmodium falciparum-infected erythrocytes. Cell Microbiol 15: 1976-1983, 2013.

52. Stocks PA, Bray PG, Barton VE, Al-Helal M, Jones M, Araujo NC, Gibbons P, Ward SA, Hughes RH, Biagini GA, Davies J, Amewu R, Mercer AE, Ellis G, and O'Neill PM. Evidence for a common non-haem chelatable-irondependent activation mechanism for semisynthetic and synthetic endoperoxide antimalarial drugs. Angew Chem Int Ed 46: 6278-6283, 2007.

53. Tripathy V and Reddy BM. Present status of understanding on the G6PD deficiency and natural selection. Postgrad Med 53: 193-202, 2007.

54. Turrini F, Giribaldi G, Carta F, Mannu F, and Arese P. Mechanisms of band 3 oxidation and clustering in the phagocytosis of Plasmodium falciparum-infected erythrocytes. Redox Rep 8: 300-303, 2003.

55. Van den Steen PE, Deroost K, Deckers J, Van Herck E, Struyf S, and Opdenakker G. Pathogenesis of malariaassociated acute respiratory distress syndrome. Trends Parasitol 29: 346-358, 2013.

56. Vippagunta SR, Dorn A, Bubendorf A, Ridley RG, and Vennerstrom JL. Deferoxamine: stimulation of hematin polymerization and antagonism of its inhibition by chloroquine. Biochem Pharmacol 58: 817-824, 1999.

57. Wassmer SC, Combes V, and Grau GE. Pathophysiology of cerebral malaria: role of host cells in the modulation of cytoadhesion. Ann N Y Acad Sci 992: 30-38, 2003.

58. William TN. Human red blood cell polymorphisms and malaria. Curr Opin Microbiol 9: 1-7, 2006.

59. Zerez CR, Roth EF, Jr., Schulman S, and Tanaka KR. Increased nicotinamide adenine dinucleotide content and synthesis in Plasmodium falciparum-infected human erythrocytes. Blood 75: 1705-1710, 1990.

Address correspondence to: Dr. Elisabeth Davioud-Charvet UMR 7509 Centre National de la Recherche Scientifique-University of Strasbourg European School of Chemistry, Polymers and Materials (ECPM)

25, Rue Becquerel Strasbourg 67087 France

E-mail: elisabeth.davioud@unistra.fr 
Date of first submission to ARS Central, July 10, 2014; date of final revised submission, January 28, 2015; date of acceptance, February 24, 2015.

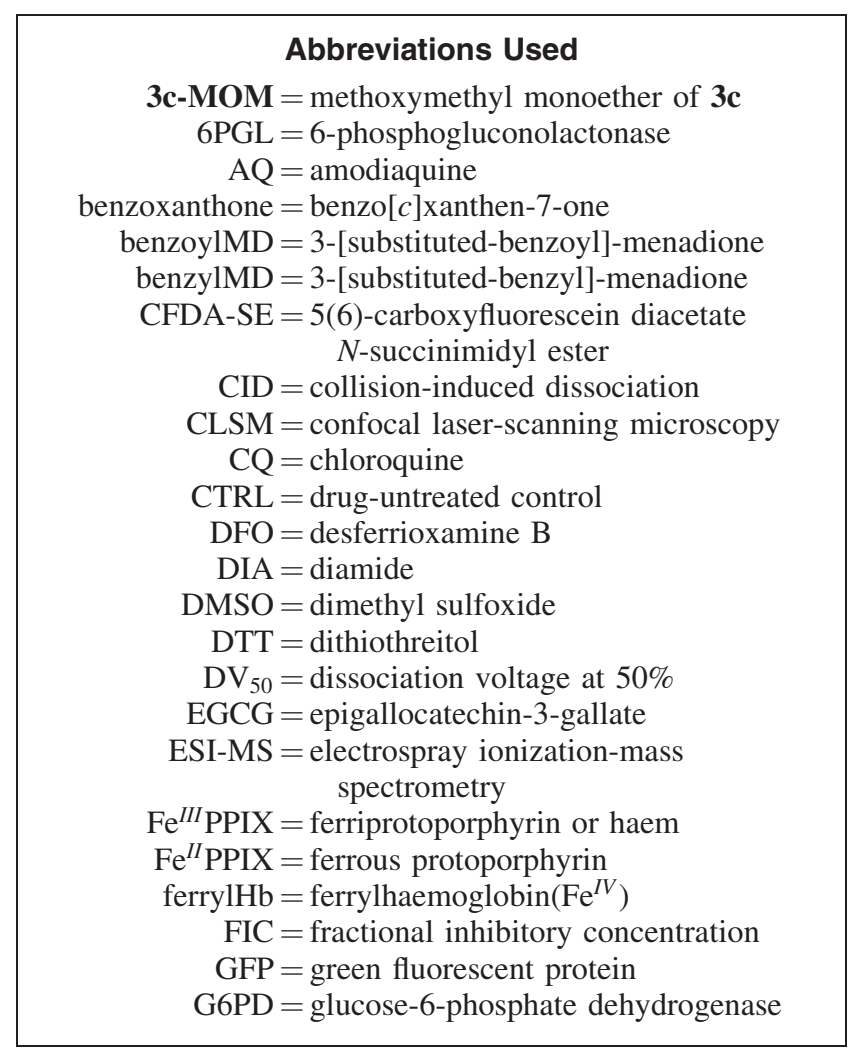

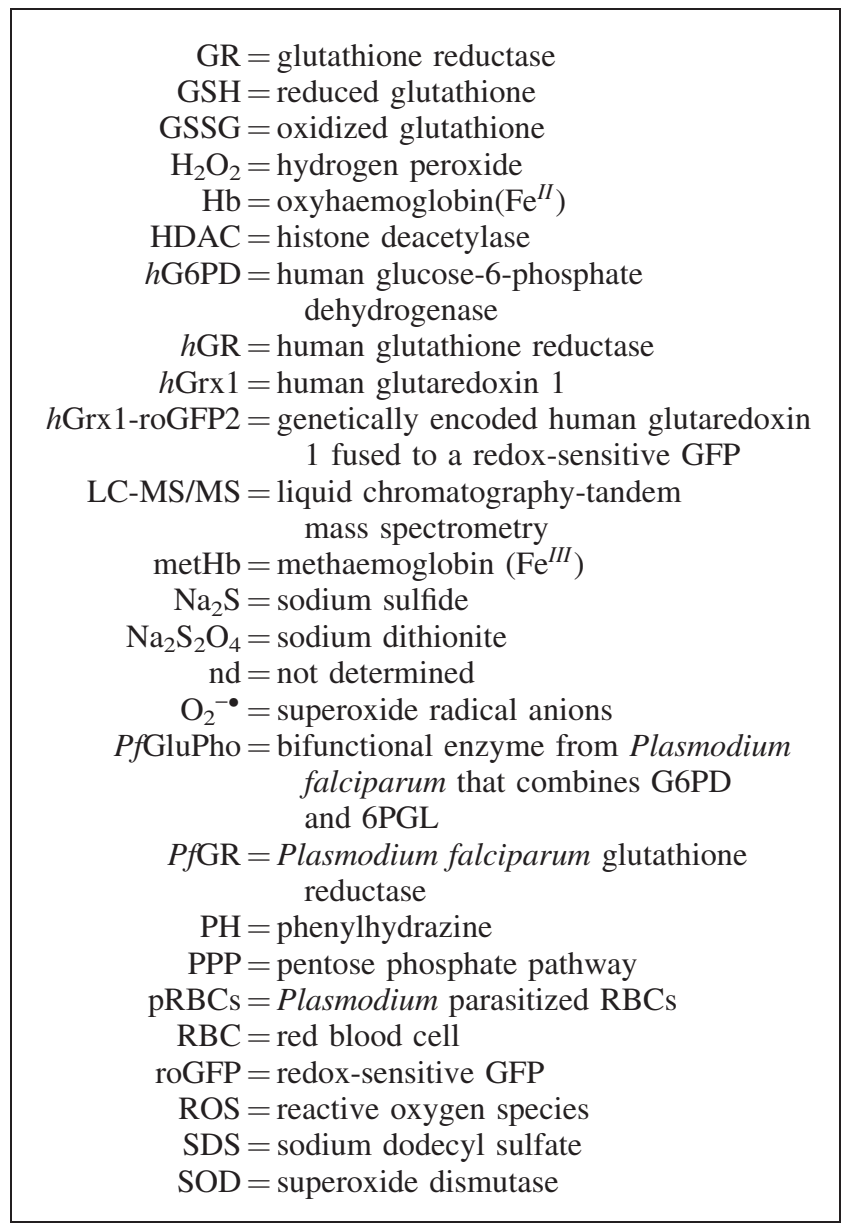

